\title{
Non-recovery of two spotted and spinner dolphin populations in the eastern tropical Pacific Ocean
}

\author{
Tim Gerrodette ${ }^{1, *, * *}$, Jaume Forcada ${ }^{1,2}$ \\ ${ }^{1}$ NOAA Fisheries, Southwest Fisheries Science Center, 8604 La Jolla Shores Drive, La Jolla, California 92037, USA \\ ${ }^{2}$ Present address: British Antarctic Survey, Natural Environment Research Council, Madingley Road, Cambridge CB3 0ET, UK
}

\begin{abstract}
Populations of northeastern offshore spotted dolphins Stenella attenuata attenuata and eastern spinner dolphins $S$. longirostris orientalis have been reduced because the dolphins are bycatch in the purse-seine fishery for yellowfin tuna in the eastern tropical Pacific Ocean (the 'tuna-dolphin issue'). Abundance and trends of these dolphin stocks were assessed from 12 large-scale pelagic surveys carried out between 1979 and 2000. Estimates of abundance were based on a multivariate linetransect analysis, using covariates to model the detection process and group size. Current estimates of abundance are about 640000 northeastern offshore spotted dolphins $(\mathrm{CV}=0.17)$ and 450000 eastern spinner dolphins $(\mathrm{CV}=$ 0.23). For the whole period from 1979 to 2000, annual estimates of abundance ranged from 494000 to 954000 for northeastern offshore spotted dolphins and from 271000 to 734000 for eastern spinner dolphins. Management actions by USA and international fishing agencies over 3 decades have successfully reduced dolphin bycatch by 2 orders of magnitude, yet neither stock is showing clear signs of recovery. Possible reasons include underreporting of dolphin bycatch, effects of chase and encirclement on dolphin survival and reproduction, longterm changes in the ecosystem, and effects of other species on spotted and spinner dolphin population dynamics.
\end{abstract}

KEY WORDS: Bycatch · Tuna-dolphin issue - Abundance - Eastern tropical Pacific $\cdot$ Stenella attenuata $\cdot$ Stenella longirostris $\cdot$ Population recovery $\cdot$ Fishery interactions

Resale or republication not permitted without written consent of the publisher

\section{INTRODUCTION}

The bycatch of dolphins by the purse-seine tuna fishery in the eastern tropical Pacific Ocean (ETP), also known as the 'tuna-dolphin issue' (Gerrodette 2002), has been the subject of considerable scientific study

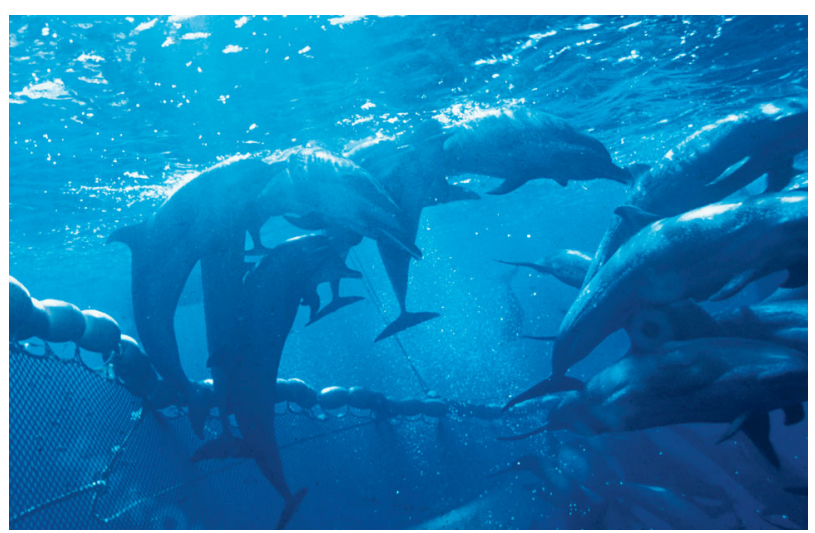

Spotted dolphins Stenella attenuata and tuna purse-seine net in the eastern tropical Pacific. Fishermen use the association of tunas, dolphins and seabirds to locate large yellowfin tuna Thunnus albacares. The dolphin bycatch, which earlier led to population declines, is now much lower, but the dolphin populations have not yet recovered

and management actions over the past 30 years. Purseseine fishing for tuna in the ETP can be carried out in 3 ways, only one of which has significant bycatch of dolphins; the other modes of fishing have bycatch of fishes, sharks and turtles, but rarely dolphins (Edwards \& Perkins 1998, Hall 1998). The part of the fishery that affects dolphins utilizes the association of seabirds, dolphins and fishes to locate and catch schools of yellowfin tuna Thunnus albacares (Au \& Pitman 1986, NRC 1992). The large bycatch of dolphins in the 1960s and early 1970s led to the decline of several stocks of pantropical spotted and spinner dolphins, Stenella attenuata and S. longirostris (Smith 1983, Wade 1993). The 1972 passage of the USA Marine Mammal Protection Act and its subsequent amendments led, by 1980, to a $95 \%$ reduction of dolphin bycatch by USA fishing 
vessels, due to a combination of scientific studies, increased regulations, observers on fishing boats, gear inspections and reviews of captain performance (Gosliner 1999). Similar programs, which were voluntary at first and later became formal agreements, were initiated in the 1980s and 1990s under the auspices of the Inter-American Tropical Tuna Commission to cover fishing vessels of the international fleet (Joseph 1994). During the 1990s the USA restricted the importation and sale of canned tuna caught by setting on dolphins. As a result of these combined actions, dolphin bycatch in the ETP has declined by $99 \%$ in the international fishing fleet, and has been eliminated by the USA fleet, which does not set on dolphins. The annual number of dolphins reported killed by the purse-seine tuna fishery is currently $<0.1 \%$ of the population size for each ETP dolphin stock (Bayliff 2004).

Estimates of dolphin abundance are used to set annual limits on the dolphin bycatch under an international agreement to conserve dolphin populations (Hedley 2001). Abundance estimates are also used in population models to assess the status of the dolphin stocks (Wade et al. 2002, Hoyle \& Maunder 2004). The surveys from 1998 to 2000 were part of a larger research effort to determine whether the fishery is having a significant adverse impact on the dolphin populations (Reilly et al. 2005). The answer to this question has biological and economic consequences, because if the fishery is not having a significant impact, the USA may adopt a less restrictive definition of 'Dolphin-Safe' tuna. ${ }^{1}$ Under current fishing practices, this re-definition would allow more canned tuna, particularly yellowfin tuna caught by the large Mexican fleet, to be sold as Dolphin-Safe in the USA and other countries. On Dec. 31, 2002, the Secretary of Commerce of the USA decided that the fishery is not having a significant adverse impact. However, this determination was challenged in court and overturned in August, 2004, on the basis that the decision was not based on science.

To assess the results of management actions, research vessel surveys to estimate abundance of the affected dolphin stocks have been carried out periodically since the 1970 s by the National Oceanic and Atmospheric Administration (NOAA Fisheries). The latest series of cruises were undertaken in 1998 to 2000. Abundance estimates based on cruises from

\footnotetext{
${ }^{1}$ Under US law, the definition of Dolphin-Safe tuna is tuna caught by methods that do not involve the intentional chase and encirclement of dolphins. The proposed change in definition would allow tuna caught by chasing and encircling dolphins to be labelled Dolphin-Safe as long as no dolphins were killed or seriously injured on that particular set of the purse seine. In either case the fishing vessel must carry an observer to certify that the standard has been met
}

1986 to 1990 have been published as annual estimates for dolphins (Wade \& Gerrodette 1992) and as pooled estimates over the entire $5 \mathrm{yr}$ period for all cetacean species (Wade \& Gerrodette 1993). These estimates were based on conventional line-transect analysis (Buckland et al. 2001).

Recent advances in line-transect analysis permit modeling the probability of detecting objects along the trackline as a function of factors other than perpendicular distance alone (Ramsey et al. 1987, Marques \& Buckland 2003, Forcada et al. 2004, Royle et al. 2004). In addition, improved estimates of distances from ship to sighting (Lerczak \& Hobbs 1998, Kinzey \& Gerrodette 2001, 2003) and group size (Gerrodette et al. 2002) are now available. In this study we used multivariate methods to estimate the abundance of spotted and spinner dolphins most affected by the ETP tuna fishery. The estimates were based on data collected from 1998 to 2000, together with a reanalysis of data from past cruises dating back to 1979. The entire set of estimates was analyzed for temporal trends, since recovery of the populations is expected after fisheryrelated mortality has been reduced to a low level.

\section{MATERIALS AND METHODS}

Stocks and survey design. Dolphin species in the eastern tropical Pacific have been divided into stocks for management purposes, using data on distribution, population dynamics, morphology and genetics (Dizon et al. 1994). Two stocks designated as depleted under the USA Marine Mammal Protection Act, and therefore of primary interest in designing the surveys, were the northeastern offshore stock of pantropical spotted dolphins Stenella attenuata attenuata north of $5^{\circ} \mathrm{N}$ and east of $120^{\circ} \mathrm{W}$ (Perrin et al. 1994), and the ETP endemic eastern subspecies of spinner dolphins $S$. longirostris orientalis (Perrin 1990). These stocks will be referred to as NE offshore spotted (NEOS) and eastern spinner (ES) dolphins, respectively. The stratification of the 1998-2000 surveys (Fig. 1D) was based on the distribution of these stocks. The core stratum includes the entire range of NE offshore spotted dolphins by definition, and most of the range of eastern spinner dolphins. The boundary of the outer stratum was drawn well beyond the known range of eastern spinner dolphins to be certain to include the entire population.

Stratification of the surveys from 1986 to 1990 (Fig. 1C) was different, based on the understanding of stock structure and distribution at that time (Holt et al. 1987). In this analysis, the original 4 strata of this series were increased to 6 by subdividing the Inshore and Middle strata to match the currently defined boundary 


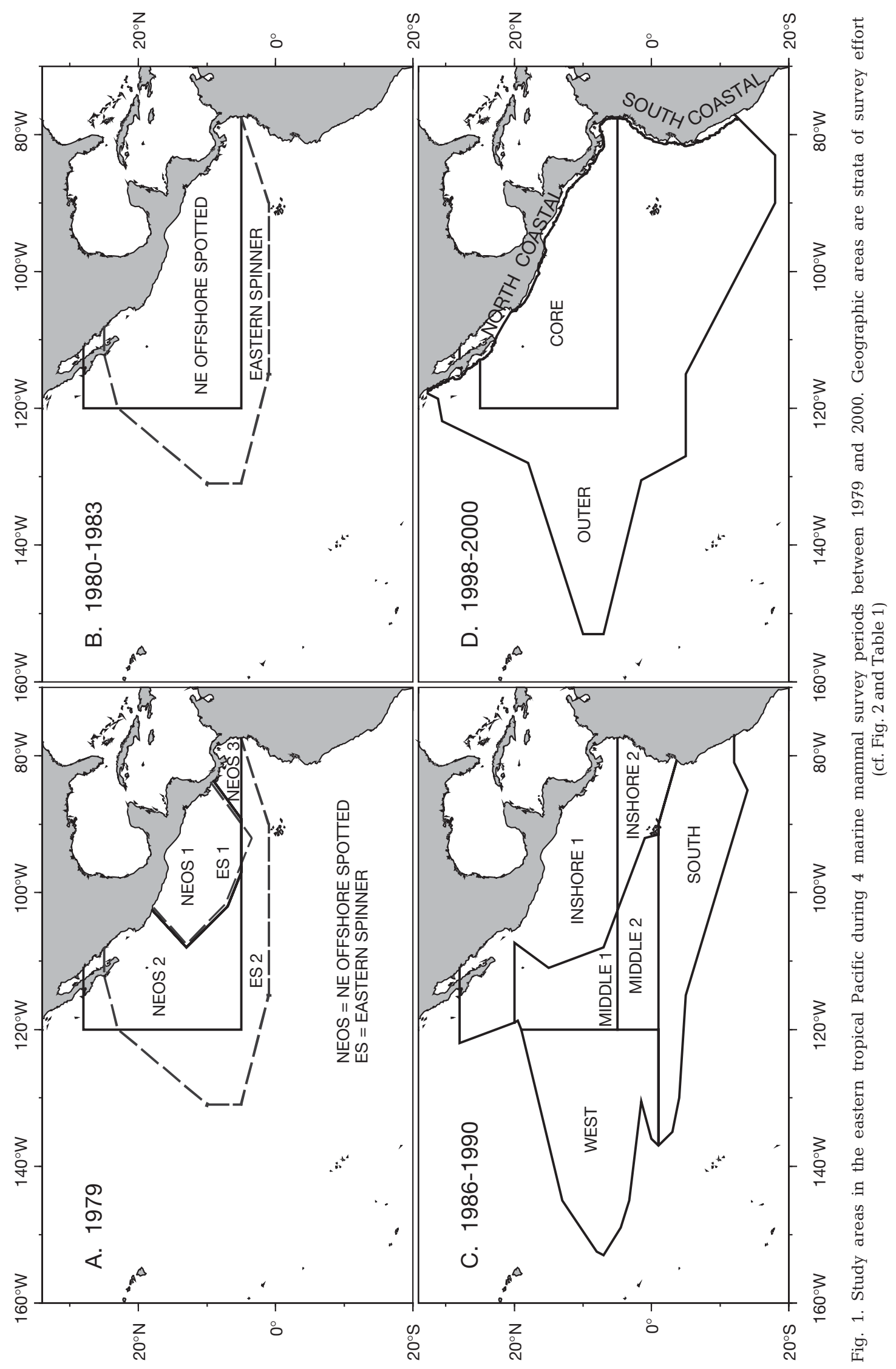


of NE offshore spotted dolphins at $5^{\circ} \mathrm{N}$. In 1980, 1982 and 1983, a single stratum was used for each stock (Fig. 1B), and the amount of transect effort within these strata was less than in other years. In 1979, effort was concentrated in a smaller 'calibration' area (Fig. 1A, areas NEOS 1 and ES 1).

The surveys were conducted with 4 vessels: RV 'David Starr Jordan', 'Townsend Cromwell', 'McArthur' and 'Endeavor', which are similar in length (52 to $57 \mathrm{~m}$ ) and observer eye height (10.4 to $10.7 \mathrm{~m})$. In 1979 and 1980, the surveys were conducted in January to March. The 1982 cruise took place in May to August and the 1983 cruise in January to April. Surveys in 1986 to 1990 and 1998 to 2000 were carried out from late July to early December. Time of year, however, should not be an important factor affecting abundance estimates, because the surveyed areas were large enough to include any seasonal movements of the dolphin populations (Reilly 1990).

Pre-determined transect lines were random within each stratum, with the constraint that spatial coverage be as even as possible. Ships moved at night, and the starting point of each day's transect effort was wherever the ship happened to be at dawn along the overall trackline. Further details of survey design and tracklines are discussed in Gerrodette \& Forcada (2002, and references therein).

Field methods. Weather permitting, a visual search for cetaceans was conducted on the flying bridge during all daylight hours as the ship moved along the trackline at a speed of 10 knots $\left(18.5 \mathrm{~km} \mathrm{~h}^{-1}\right)$. On each ship, 3 marine mammal observers stood watch at a time, 2 using pedestal-mounted $25 \times$ marine binoculars and 1 using hand-held $7 \times$ binoculars and the naked eye. When marine mammals were sighted, observers measured the angle and distance to the animals. The pedestals of the $25 \times$ binoculars were fitted with azimuth rings for measurement of horizontal angles from the trackline to the animals. Vertical angles from the horizon to the animals were measured with reticle scales in the ocular lenses of the binoculars. Reticle values were converted to angular values (Kinzey \& Gerrodette 2001) and to distance from the observer, based on height above the water (Gordon 1990, Lerczak \& Hobbs 1998). Reticle measurements of distance were checked against radar under a variety of field conditions; a slight tendency to underestimate distances beyond $4 \mathrm{~km}$, primarily due to atmospheric refraction of light, was corrected by regression (Kinzey $\&$ Gerrodette 2003). Perpendicular distance $d$ of the sighting from the trackline was computed as $d=r \sin \theta$, where $r$ was the radial distance to the sighting and $\theta$ the horizontal angle of the sighting from the trackline. In addition to angle and reticle, Beaufort sea state, visibility, sun angle, swell height, presence of birds and other factors that might affect detection probability were recorded with each sighting.

A data entry program automatically recorded the position of the ship with a GPS signal from the ship. If the sighting was $<5.6 \mathrm{~km}$ ( $3 \mathrm{n}$ miles) from the trackline, the observer team went 'off effort' and directed the ship to leave the trackline and to approach the animals sighted (closing mode survey). The observers identified the sighting to species or subspecies and made group size estimates. Observers discussed distinguishing field characteristics in order to obtain the best possible identification, but they estimated group sizes and, in the case of mixed-species schools, group composition independently. After completing the sighting, search effort was resumed toward the next waypoint. Further details of data collection procedures are given in Kinzey et al. (2000).

On cruises before 1998, the same basic data (positions at beginning and end of searching effort, angles and distances to sightings, and school sizes) were collected, although methods of collecting the data evolved over the years. For example, previous data were recorded on paper rather than on a laptop computer, and ship positions were measured with Loran or SatNav before the GPS system was available. On the 1979 and 1980 cruises, distance and angle from trackline were estimated by eye rather than with binocular reticles and angle rings.

School size. From 1987 to 2000, RV 'David Starr Jordan' carried a helicopter equipped with mediumformat, motion-compensated, military reconnaissance cameras. In suitable conditions of sea state, sun angle and school configuration, entire schools of dolphins were photographed from the helicopter and the number of dolphins was counted directly from the negatives (Gilpatrick 1993). However, aerial photographs were available for only a subset of schools seen from RV 'David Starr Jordan' and none of the schools seen from the other ships. For most schools, school size was estimated from the best, high and low estimates made by each observer.

By comparing each observer's estimates of the photographed schools to the counts from the negatives, individual correction or 'calibration' coefficients for 52 observers were estimated (Barlow et al. 1998, Gerrodette et al. 2002). These coefficients were used to produce a calibrated estimate of school size when an observer's original ('best') estimate of school size fell in the range of photographed schools for which s/he had been calibrated. Calibration coefficients were not available for every observer, either because (1) the observer worked prior to the start of the aerial calibration program in 1987, or (2) the observer had $\leq 5$ photographed schools to estimate the regression coefficients. For school size estimates made by uncalibrated 
observers, or for schools which fell outside the range of school sizes for which an observer had been calibrated, we divided the observer's best estimate by 0.860 , the mean ratio of best estimate to photo count for the 52 calibrated observers (Gerrodette et al. 2002).

We combined the individual estimates made by each observer, adjusted as described above, to obtain a single estimate of size for each school. Because the calibration procedure was based on the logarithm of the estimates, the weighting and averaging was also carried out on the logarithms, using the inverse of the variance of each observer's estimates as weights. The logarithm of the final calibrated estimate of school size $s$ for each sighting was:

$$
\ln \hat{s}=\sum_{i=1}^{n} w_{i} \ln C_{i}
$$

with variance

$$
\operatorname{var}(\ln \hat{s})=\sum_{i=1}^{n} w_{i}^{2} \operatorname{var}\left(\ln C_{i}\right)=\left(\sum_{i=1}^{n}{v_{i}}^{-1}\right)^{-1}
$$

where $n$ is the number of calibrated estimates $C$ for the school, $w_{i}=V_{i}^{-1} / \Sigma v_{i}^{-1}$ and $v_{i}=\operatorname{var}\left(\ln C_{i}\right)$ is the residual variance of the log-log regression of school size estimates on photo counts for the observer making the $i$ th estimate.

Abundance estimation. Estimation of abundance was based on distance sampling (Buckland et al. 2001). A multivariate extension of conventional line-transect analysis (Marques \& Buckland 2003, Forcada et al. 2004; see Appendix 1) estimated abundance as:

$$
\hat{N}=\sum_{j} \frac{A_{j}}{2 L_{j}} \sum_{i} \hat{f}_{i j}\left(0, C_{i j}\right) \hat{S}_{i j}
$$

where $A_{j}$ is the area and $L_{j}$ is the length of search effort in stratum $j, \hat{f}_{i j}\left(0, C_{i j}\right)$ is the estimated probability density evaluated at zero perpendicular distance of the $i$ th sighting in stratum $j$ under conditions $C_{i j}$, and $\hat{s}_{i j}$ is the estimated group size of the $i$ th sighting in stratum $j$ (or subgroup size of the species of interest in the case of mixed-species schools). Estimation was based on search effort and sightings that occurred during oneffort periods, in conditions of Beaufort $<6$ and visibility $>4 \mathrm{~km}$. The vector of covariates $C_{i j}$ included the continuous variables: group size, Beaufort sea state and time of day; and the categorical variables: species, ship, stratum, sighting cue, whether the school was a single- or mixed-species group, presence/absence of glare on the trackline, and presence/absence of seabirds. Sea state measured on the Beaufort scale was actually a discrete variable, but the ordinal scale could be modeled satisfactorily as a continuous variable (Barlow et al. 2001). The continuous variable swell height was also recorded on the 1998-2000 cruises. All dolphin schools on or near the trackline were assumed to be detected, i.e. $g(0)=1.0$.
We explored half-normal and hazard-rate models, each with variable numbers and types of covariates. Hazard-rate models gave highly variable estimates of effective strip width among years, and unpublished analyses suggested grounds for biased $f_{i j}\left(0, C_{i j}\right)$ estimates using this model for the study data. For consistency we used only the half-normal model, with sightings truncated at $5.5 \mathrm{~km}$. For each species or stock in each year, covariates were tested singly and in additive combination, and a set of best models was chosen on the basis of Akaike's Information Criterion corrected for sample size $\left(\mathrm{AIC}_{\mathrm{C}}\right.$ ) (Hurvich \& Tsai 1989). For computational efficiency, we retained as reasonable models all models with an $\mathrm{AIC}_{\mathrm{C}}$ difference $(\triangle \mathrm{AIC}) \leq 2$ from the best model. Final estimates of $f_{i j}\left(0, C_{i j}\right)$ utilized model averaging, with the $\mathrm{AIC}_{\mathrm{C}}$ scores as weighting factors. The weight of the estimate from the $j$ th model was $\exp \left(-0.5 \Delta \mathrm{AIC}_{j}\right) / \Sigma_{j} \exp \left(-0.5 \Delta \mathrm{AIC}_{j}\right)$ (Burnham \& Anderson 1998).

Pooled components of the abundance estimates were computed to provide additional summary and diagnostic statistics. Pooled components $\hat{f}(0)$, expected school size $\widehat{E(S)}$, school encounter rate $n / L$, and percentage of the total abundance estimate due to the prorated abundance of unidentified sightings (see next section) were calculated across all sightings $i$ and strata $j$ as:

$$
\begin{aligned}
& \hat{f}(0)=\sum_{j} \sum_{i} \hat{f}_{i j}\left(0, c_{i j}\right) / \sum_{j} n_{j} \\
& \widehat{E(s)}=\sum_{j} \sum_{i} \hat{f}_{i j}\left(0, c_{i j}\right) \hat{S}_{i j} / \sum_{j} \sum_{i} \hat{f}_{i j}\left(0, c_{i j}\right) \\
& n / L=\sum_{j} n_{j} / \sum_{j} L_{j} \\
& \% \text { pro }=100 \sum_{j} \hat{N}_{\text {unid }_{i j}} / \sum_{j}\left(\hat{N}_{\text {unid }, j_{j}}+\hat{N}_{i d, j}\right)
\end{aligned}
$$

for each stock and year, where, for stratum $j, n_{j}$ is the number of sightings, $\hat{N}_{i d, j}$ is the estimated abundance based on identified sightings, $\hat{N}_{u n i d, j}$ is the prorated abundance estimate based on unidentified sightings, and other terms are defined in Eq. (3).

Specific code in $\mathrm{S}$ was written to implement the analysis. The $\mathrm{S}$ code included calls to FORTRAN routines for the maximum likelihood optimization of the covariate density models. These routines consisted of modifications of Buckland's (1992) algorithm to fit maximum-likelihoods of density functions using the Newton-Raphson method.

Unidentified sightings. Not all sightings could be identified to stock with certainty. The number of sightings recorded as unidentified was first reduced by assigning sightings recorded as 'probable' to that identified category. For the remaining unidentified sightings, we estimated abundance for the unidentified category and prorated abundance among appropriate 
stocks in proportion, by stratum, to the estimated abundance from identified sightings of those stocks that were included in the broader unidentified category. The general form of the proration was:

$$
\hat{N}_{i j}=\hat{N}_{i j}^{*}+\hat{N}_{u j}\left(\frac{\hat{N}_{i j}^{*}}{\hat{N}_{i j}^{*}+\sum_{k} \hat{N}_{k j}^{*}}\right)
$$

where $\hat{N}_{i j}$ is the revised abundance estimate of stock $i$ in stratum $j, \hat{N}^{*}$ ij is the abundance of stock $i$ in stratum $j$ estimated from identified sightings of stock $i, \hat{N}_{u j}$ is the abundance of the unidentified category estimated from unidentified sightings in stratum $j$, and $\hat{N}^{*}{ }_{k j}$ is the abundance estimate of stock $k$ in stratum $j$ for stocks other than $i$ included in the unidentified sighting category. This proration made the assumption that all taxa within the unidentified category were equally easy to identify. While probably unrealistic, this assumption was the simplest in the absence of data on ease of identification.

We estimated abundance of 3 unidentified sighting categories: unidentified spotted dolphins (prorated to NE offshore spotted, western/southern offshore spotted, and coastal spotted dolphins), unidentified spinner dolphins (prorated to eastern spinner and whitebelly spinner dolphins), and unidentified dolphins (prorated among several species including spotted and spinner dolphins). For example, to prorate the abundance represented by sightings of unidentified dolphins, we estimated abundance of spotted, spinner, striped ( $S$. coeruleoalba), common (Delphinus spp.), bottlenose (Tursiops truncatus), rough-toothed (Steno bredanensis) and Risso's (Grampus griseus) dolphins in each stratum, and distributed the abundance of unidentified dolphins proportionally among them.

Precision. Precision of the abundance estimates and pooled abundance components was estimated by balanced nonparametric bootstrap (Davison \& Hinkley 1997). Within each stratum, a balanced bootstrap sample was constructed by sampling transects (days on effort) with replacement, so that all transects were selected the same number of times in total. To include the variability due to school size estimation and the calibration procedure, for each school size estimate $\hat{s}$ in the bootstrap sample, the logarithm of a new school size was chosen from a normal distribution with mean $\ln (\hat{s})$ and variance $\operatorname{var}[\ln (\hat{s})]$, equal to the estimated mean and variance of the sighting's school size estimate obtained by calibration. For each bootstrap sample, the full estimation procedure was carried out, including proration and model averaging. To include model selection uncertainty and to avoid overestimating precision, multiple models were used in each bootstrap. Models for $f_{i j}\left(0, C_{i j}\right)$ estimation were restricted to the set of models with $\Delta \mathrm{AIC} \leq 2$, based on the original data, plus the univariate half-normal model. From 1000 bootstrap estimates, the standard errors (SE), coefficients of variation (CV) and bias corrected and accelerated $\left(\mathrm{BC}_{\mathrm{a}}\right.$ ) (Efron \& Tibshirani 1993) $95 \%$ confidence intervals of the estimates of total abundance and pooled abundance components were computed.

Trend estimation. To examine trends in the timeseries, we fitted weighted linear and quadratic (2ndorder) models to the estimates of NE offshore spotted and eastern spinner dolphins, using the inverse of the variance of each point estimate as the weighting factor. The statistical significance of each model was tested against the null hypothesis of no change in population size with time, using a Type 1 error rate of $\alpha=$ 0.05 . The statistical power ( 1 - Type 2 error rate) of detecting a change in population size, given the actual number of estimates at the observed intervals and precision, was evaluated for simple exponential growth, using a modified version of Trends, a program to estimate power for linear regression (Gerrodette 1987, 1993). The power analysis assumed a 2-tailed test of significance with $\alpha=0.05$, rates of population growth from 1 to $5 \%$ and the mean CV for NE offshore spotted dolphins. To provide visual summaries of the timeseries, the estimates were smoothed with nonparametric LOESS smoothers, using the same inverse-variance weights.

\section{RESULTS}

\section{Sightings and effort}

Total transect effort was $42000 \mathrm{~km}$ in 1998 with 3 ships, and $30000 \mathrm{~km}$ each in 1999 and 2000 with 2 ships (Table 1). During the 1986-1990 cruises, total search effort ranged from about 24000 to $30000 \mathrm{~km}$ each year, while total effort in 1983 and earlier was from 8600 to 16100 within the strata shown in Fig. 1. Total effort for all years was $295000 \mathrm{~km}$, but the amount and distribution varied among years (Fig. 2, Table 1).

The annual number of sightings (schools) of NE offshore spotted dolphins ranged from 107 to 184 in 1998 to 2000 (core and north coastal strata), from 60 to 88 in 1986 to 1990 (Inshore 1 and Middle 1 strata) and from 20 to 56 from 1979 to 1983 (Table 1, Fig. 2). The annual number of sightings of eastern spinner dolphin schools ranged from 67 to 94 in 1998 to 2000, from 38 to 71 in 1986 to 1990 and from 14 to 30 in 1979 to 1983. By design, more effort was concentrated in the range of NE offshore spotted and eastern spinner dolphins in 1998 to 2000 compared to previous years (Table 1, Fig. 2). The number of sightings of these dolphin stocks therefore tended to be higher, particularly in 1998 when 3 ships were used. 
Table 1. Size of study area for surveys of Stenella attenuata attenuata and $S$. longirostris orientalis, amount of survey effort and number of sightings, by year and stratum. Sightings: number of identified dolphin schools within $5.5 \mathrm{~km}$ perpendicular distance of the trackline during periods of searching effort in conditions of Beaufort $<6$ and visibility $>4 \mathrm{~km}$. Strata are shown in Fig. 1. Distribution of effort and sightings is shown in Fig. 2

\begin{tabular}{|c|c|c|c|c|}
\hline Stratum & $\begin{array}{c}\text { Area } \\
\left(10^{6} \mathrm{~km}^{2}\right)\end{array}$ & $\begin{array}{c}\text { Effort } \\
(\mathrm{km})\end{array}$ & $\begin{array}{c}\text { Sightings (n } \\
\text { Offshore } \\
\text { spotted }\end{array}$ & $\begin{array}{l}\text { of schools) } \\
\text { Eastern } \\
\text { spinner }\end{array}$ \\
\hline \multicolumn{5}{|l|}{1979} \\
\hline NEOS 1 & 2.302 & 8785 & 51 & - \\
\hline NEOS 2 & 3.895 & 3758 & 5 & - \\
\hline NEOS 3 & 0.371 & 62 & 0 & - \\
\hline ES 1 & 2.398 & 9135 & - & 29 \\
\hline ES 2 & 7.232 & 4397 & - & 1 \\
\hline \multicolumn{5}{|l|}{1980} \\
\hline NE offshore spotted & 6.568 & 6103 & 36 & - \\
\hline Eastern spinner & 9.630 & 9965 & - & 14 \\
\hline \multicolumn{5}{|l|}{1982} \\
\hline NE offshore spotted & 6.568 & 5631 & 20 & - \\
\hline Eastern spinner & 9.630 & 6575 & - & 15 \\
\hline \multicolumn{5}{|l|}{1983} \\
\hline NE offshore spotted & 6.568 & 4347 & 24 & - \\
\hline Eastern spinner & 9.630 & 4209 & - & 14 \\
\hline \multicolumn{5}{|l|}{1986} \\
\hline Inshore 1 & 4.603 & 9077 & 59 & 42 \\
\hline Inshore 2 & 1.400 & 2630 & 10 & 1 \\
\hline Middle 1 & 2.000 & 3345 & 18 & 15 \\
\hline Middle 2 & 1.810 & 4317 & 15 & 0 \\
\hline West & 5.218 & 3848 & 16 & 3 \\
\hline South & 4.539 & 3882 & 5 & 0 \\
\hline \multicolumn{5}{|l|}{1987} \\
\hline Inshore 1 & 4.603 & 8361 & 58 & 38 \\
\hline Inshore 2 & 1.400 & 2934 & 2 & 0 \\
\hline Middle 1 & 2.000 & 4327 & 21 & 14 \\
\hline Middle 2 & 1.810 & 3655 & 23 & 0 \\
\hline West & 5.218 & 3823 & 15 & 2 \\
\hline South & 4.539 & 4492 & 12 & 0 \\
\hline \multicolumn{5}{|l|}{1988} \\
\hline Inshore 1 & 4.603 & 7336 & 49 & 31 \\
\hline Inshore 2 & 1.400 & 2065 & 4 & 2 \\
\hline Middle 1 & 2.000 & 3530 & 11 & 4 \\
\hline Middle 2 & 1.810 & 2648 & 7 & 0 \\
\hline West & 5.218 & 3209 & 16 & 1 \\
\hline South & 4.539 & 5019 & 5 & 0 \\
\hline \multicolumn{5}{|l|}{1989} \\
\hline Inshore 1 & 4.603 & 9006 & 72 & 54 \\
\hline Inshore 2 & 1.400 & 2719 & 7 & 0 \\
\hline Middle 1 & 2.000 & 4303 & 16 & 14 \\
\hline Middle 2 & 1.810 & 3597 & 16 & 2 \\
\hline West & 5.218 & 3659 & 15 & 1 \\
\hline South & 4.539 & 4788 & 7 & 0 \\
\hline \multicolumn{5}{|l|}{1990} \\
\hline Inshore 1 & 4.603 & 7321 & 60 & 29 \\
\hline Inshore 2 & 1.400 & 2727 & 3 & 0 \\
\hline Middle 1 & 2.000 & 4652 & 19 & 12 \\
\hline Middle 2 & 1.810 & 4211 & 18 & 2 \\
\hline West & 5.218 & 5484 & 11 & 2 \\
\hline South & 4.539 & 6556 & 8 & 0 \\
\hline \multicolumn{5}{|l|}{1998} \\
\hline Core & 5.869 & 19508 & 158 & 74 \\
\hline Outer & 14.778 & 17103 & 44 & 8 \\
\hline North coastal & 0.535 & 4403 & 26 & 12 \\
\hline South coastal & 0.171 & 762 & 2 & 0 \\
\hline \multicolumn{5}{|l|}{1999} \\
\hline Core & 5.869 & 15755 & 101 & 63 \\
\hline Outer & 14.778 & 11732 & 31 & 0 \\
\hline North coastal & 0.535 & 2001 & 6 & 4 \\
\hline South coastal & 0.171 & 89 & 0 & 0 \\
\hline \multicolumn{5}{|l|}{2000} \\
\hline Core & 5.869 & 15005 & 102 & 60 \\
\hline Outer & 14.778 & 11355 & 28 & 0 \\
\hline North coastal & 0.535 & 2786 & 5 & 7 \\
\hline South coastal & 0.171 & 415 & 0 & 0 \\
\hline
\end{tabular}

In addition to the identified sightings in Table 1, there was a large number of unidentified dolphin sightings each year. An unidentified dolphin sighting could potentially be any of a number of species, including spotted and spinner dolphins. Unidentified dolphin sightings were usually small groups of animals seen at large radial distances from the ship that subsequently could not be relocated, or groups seen at $>5.6 \mathrm{~km}$ from the trackline that were not approached for identification. Although the number of unidentified dolphin schools was large, the contribution of these sightings to total abundance was small (see 'Abundance' below) because many of the sightings were beyond the truncation distance of $5.5 \mathrm{~km}$, group size was small, and only a fraction of the estimated unidentified dolphin abundance was prorated to the stocks of interest.

\section{Model selection, detection function, and group size}

Models including school size, sea state, sighting cue and other covariates were important in modeling the probability of detecting schools of spotted and spinner dolphins (Table 2). The number of plausible models $(\triangle \mathrm{AIC} \leq 2)$ ranged from 1 to 5 , with multiple models chosen in most years. A univariate model with perpendicular distance as the only predictor was chosen as the best model in about half the cases, but it was never the only model chosen. The number of covariates selected ranged from 1 to 3 , with group size being the most frequently selected covariate. In general, estimation of $f_{i j}\left(0, C_{i j}\right)$ was based on sightings of a particular stock (Table 1). However, if the number of sightings of a single stock was not adequate (usually a minimum of about 40), sightings of all stocks within species were combined for $f_{i j}\left(0, C_{i j}\right)$ estimation. In 1980, 1982 and 1983, when the amount of survey effort and number of sightings were small, we combined spotted and spinner sightings for $f_{i j}\left(0, C_{i j}\right)$ estimation, because the species are similar in body and school size and, indeed, often occur together in the same school. Although different models were generally selected (Table 2), the mean estimates of $f(0)$ were similar (Table 3).

The histograms of sighting frequency by perpendicular distance for spotted (Fig. 3) and spinner (Fig. 4) dolphins frequently showed a spike in the frequency of sightings near the trackline. As noted in 'Materials and methods', fitting the probability density function to this spike with 
hazard-rate models gave unreasonable values for the effective strip width, and unpublished simulations suggested that estimates of $f_{i j}\left(0, C_{i j}\right)$ based on these models could be biased. Therefore, we used the half-normal model in all years for both species, with the scale modified by the covariates $C_{i j}$ for each sighting. This approach also enabled a more consistent series of abundance estimates to evaluate trends in abundance. The $f(0)$ values shown in Figs. $3 \& 4$ were fit with a univariate half-normal model for a visual summary only, and thus do not necessarily agree with the values in Table 3, which include the effects of the covariates.

Dolphin school sizes were large, highly variable, and had strongly skewed distributions (Fig. 5). Occasional large schools of up to 2600 dolphins were observed. A single very large dolphin school can significantly influence mean group size, and the presence or absence of these large but rarely encountered schools contributed to variability among years. An adaptive kernel density estimator was used to improve the bootstrap sampling of group size (Forcada 2002). Across all years, the mean observed school size was slightly larger for spinner than for spotted dolphins (122 vs. 114). The school size values shown in Fig. 5 include bias correction due to school size estimation tendencies (the calibration procedure) only, and thus do not agree exactly with the values in Table 3, which include the effects of the covariates.

\section{Abundance \\ Estimated abundance of NE offshore spotted dolphins ranged from 494000 in 1986 to 954000 in 1989, while es- timated abundance of eastern spinner dolphins ranged from 271000 in 1980 to 734000 in 1989 (Table 3, Fig. 6). Coefficients of variation (CVs) ranged from 13.5 to $37.1 \%$ for NE offshore spotted dolphins, and from 21.8 to}

$40.9 \%$ for eastern spinner dolphins. In general, estimates were more precise in the recent (1998 to 2000) surveys than in the earlier surveys, and estimates of NE offshore spotted dolphins were more precise than estimates of eastern spinner dolphins (Table 3, Fig. 6).

Estimates of pooled components of abundance indicated the contribution of effective strip width, school size, encounter rate and proration of unidentified sightings to each abundance estimate (Table 3). Annual $f(0)$ s ranged from 0.25 to $0.46 \mathrm{~km}^{-1}$, implying effective strip widths of 2 to $4 \mathrm{~km}$ on either side of the trackline, depending on the conditions each year. Spotted and spinner dolphins had similar effective strip widths each year; the mean annual difference was $0.13 \mathrm{~km}$. Averaged across years, the effective strip width was $3.1 \mathrm{~km}$ on either side of the trackline for both spotted and spinner dolphins. Annual mean school sizes ranged from 62 to 220 for NE offshore spotted and from 73 to 151 for eastern spinner dolphins (corrected for bias due to school size and other sighting covariates, as well as bias due to individual observer estimation tendency). The average of the annual means for these 2 stocks was 108.5 and 109.3, respectively. Encounter rates were 0.385 to 0.934 schools per $100 \mathrm{~km}$ for NE offshore spotted dolphins and 0.141 to 0.333 for eastern spinner dolphins. Unlike $f(0)$ and school size, encounter rates varied greatly by stratum due to the distribution of the stocks (Fig. 2). Therefore, pooled encounter rates were less informative than pooled $f(0)$ and school size. In particular, because effort and encounter rate varied by stratum, multiplication of the pooled abundance components in Table 3 may not approximate the estimates of abundance. The contribution of unidentified sightings to the estimated abundance of each stock varied by year, but averaged $4.5 \%$ for NE offshore spotted and $4.8 \%$ for eastern spinner dolphins.

Table 2. Models for $f_{i j}\left(0, C_{i j}\right)$ estimation of the abundance of dolphins Stenella attenuata and S. longirostris, by year and species. Entries in the table show the variables (perpendicular distance plus covariates) of the models, in the order selected by $\mathrm{AIC}_{\mathrm{c}}$, used with the half-normal model for estimation of $f_{i j}\left(0, C_{i j}\right)$ for that species and year. If more than one model is shown, model averaging was used. Variables within a model are connected with ' + '. pd: perpendicular distance, st: stratum, sp: species (stock), gs: group (total school) size, t: time of day, s: ship, bf: Beaufort sea state, sh: swell height, b: birds present and sc: sighting cue

\begin{tabular}{|c|c|c|}
\hline Year & Spotted dolphins & Spinner dolphins \\
\hline 1979 & $\mathrm{pd}, \mathrm{pd}+\mathrm{t}, \mathrm{pd}+\mathrm{gs}$ & $\mathrm{pd}, \mathrm{pd}+\mathrm{bf}, \mathrm{pd}+\mathrm{t}$ \\
\hline 1980 & pd+gs & pd+gs \\
\hline 1982 & $p d, p d+g s, p d+b$ & $p d, p d+g s, p d+b$ \\
\hline 1983 & $\mathrm{pd}, \mathrm{pd}+\mathrm{bf}$ & $\mathrm{pd}, \mathrm{pd}+\mathrm{bf}$ \\
\hline 1986 & $\mathrm{pd}+\mathrm{s}, \mathrm{pd}+\mathrm{s}+\mathrm{gl}$ & $p d, p d+s, p d+b, p d+g l, p d+b f, p d+s+t$ \\
\hline 1987 & $p d+b+b f+g l, p d+b+b f, p d+b, p d+b+t, p d+b+g l$ & $\mathrm{pd}+\mathrm{s}, \mathrm{pd}+\mathrm{s}+\mathrm{t}, \mathrm{pd}+\mathrm{s}+\mathrm{bf}$ \\
\hline 1988 & pd, pd+gl, pd+bf, pd+gs & $\mathrm{pd}, \mathrm{pd}+\mathrm{gs}, \mathrm{pd}+\mathrm{bf}$ \\
\hline 1989 & $\mathrm{pd}+\mathrm{s}, \mathrm{pd}+\mathrm{s}+\mathrm{b}, \mathrm{pd}+\mathrm{s}+\mathrm{gs}, \mathrm{pd}+\mathrm{s}+\mathrm{t}$ & $\mathrm{pd}+\mathrm{s}, \mathrm{pd}+\mathrm{s}+\mathrm{gl}, \mathrm{pd}, \mathrm{pd}+\mathrm{s}+\mathrm{t}$ \\
\hline 1990 & $\mathrm{pd}+\mathrm{gs}, \mathrm{pd}$ & $\mathrm{pd}, \mathrm{pd}+\mathrm{gs}, \mathrm{pd}+\mathrm{bf}, \mathrm{pd}+\mathrm{b}$ \\
\hline 1998 & $\mathrm{pd}+\mathrm{sc}$ & pd, pd+gs \\
\hline 1999 & $p d+g s, p d, p d+b i, p d+b f$ & $\mathrm{pd}, \mathrm{pd}+\mathrm{gs}$ \\
\hline 2000 & $\mathrm{pd}+\mathrm{gs}+\mathrm{t}, \mathrm{pd}+\mathrm{gs}$ & $p d, p d+s h, p d+b, p d+g s$ \\
\hline
\end{tabular}


Table 3. Stenella attenuata attenuata and S. longirostris orientalis. Estimates of abundance, pooled components of abundance, and measures of their precision, by stock and year. $N$ : abundance, $f(0)$ : pooled probability density function of detection evaluated at zero perpendicular distance in $\mathrm{km}^{-1}, \mathrm{E}(\mathrm{s})$ : pooled expected school size, $100 \times \mathrm{n} / \mathrm{L}$ : pooled encounter rate in sightings per $100 \mathrm{~km}$, \%pro: pooled percentage of abundance estimate contributed by unidentified sightings, SE: standard error, \%CV: coefficient of variation expressed as a percentage, and LCL and UCL are lower and upper 95\% confidence limits

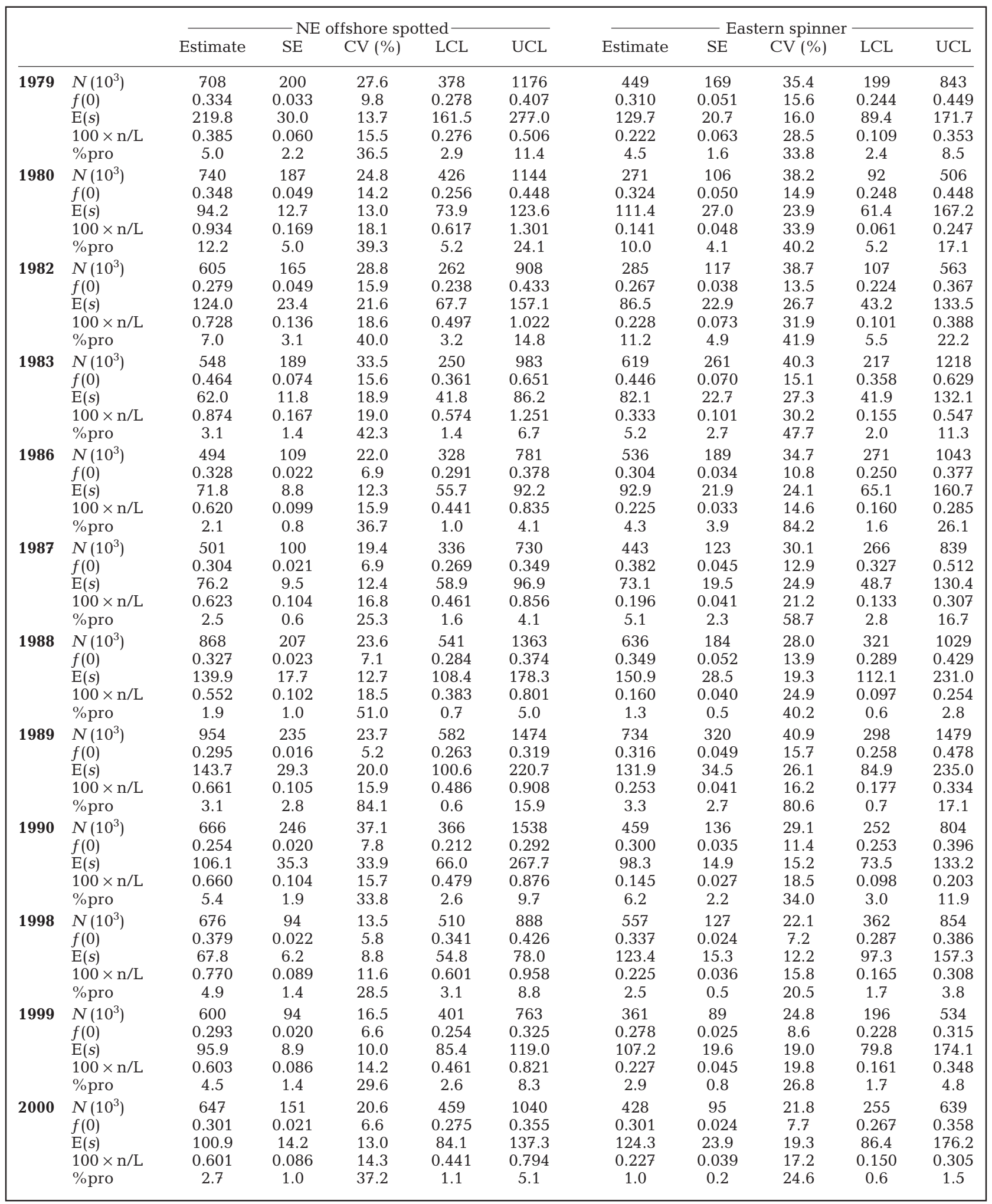




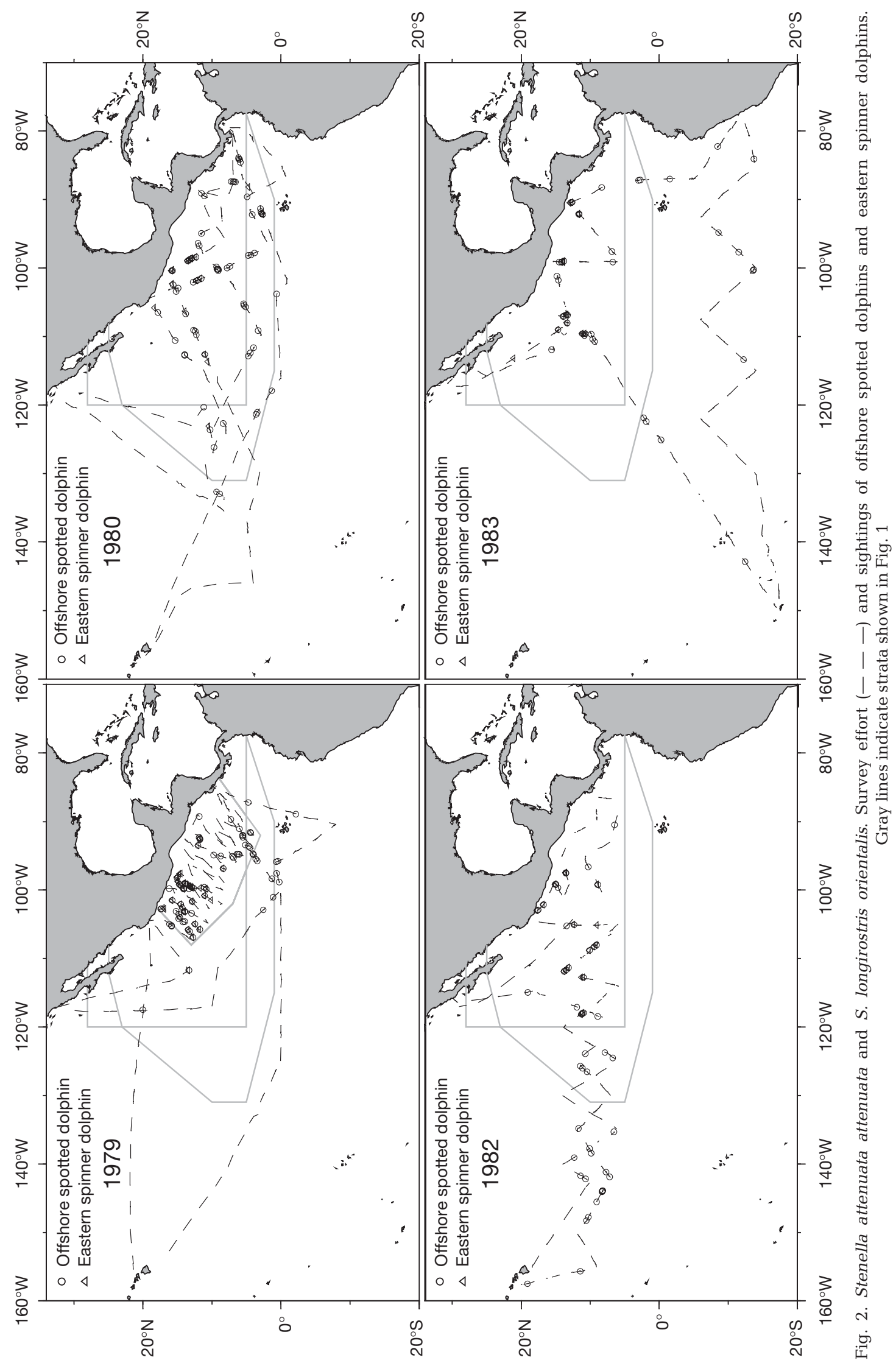




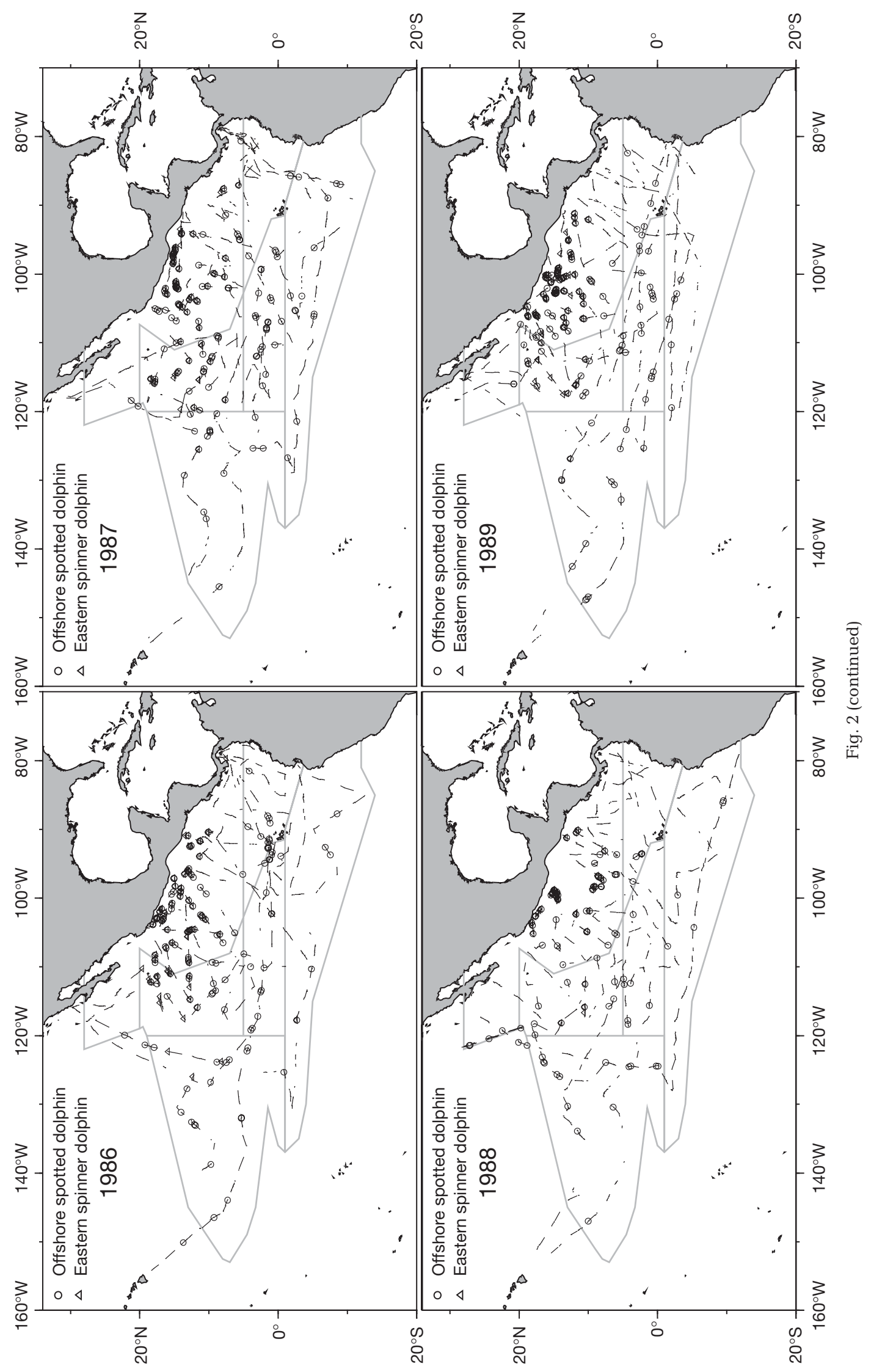




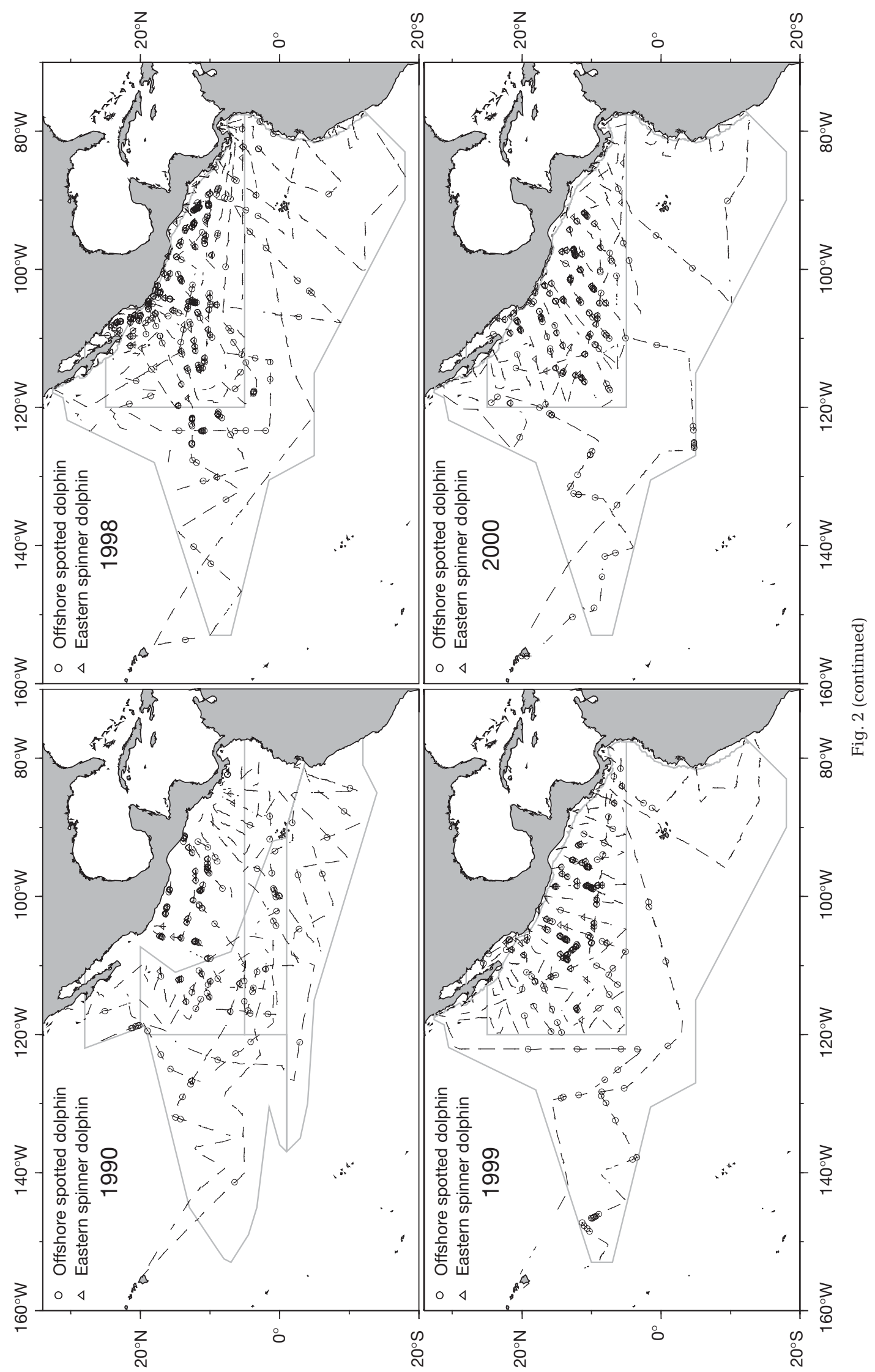



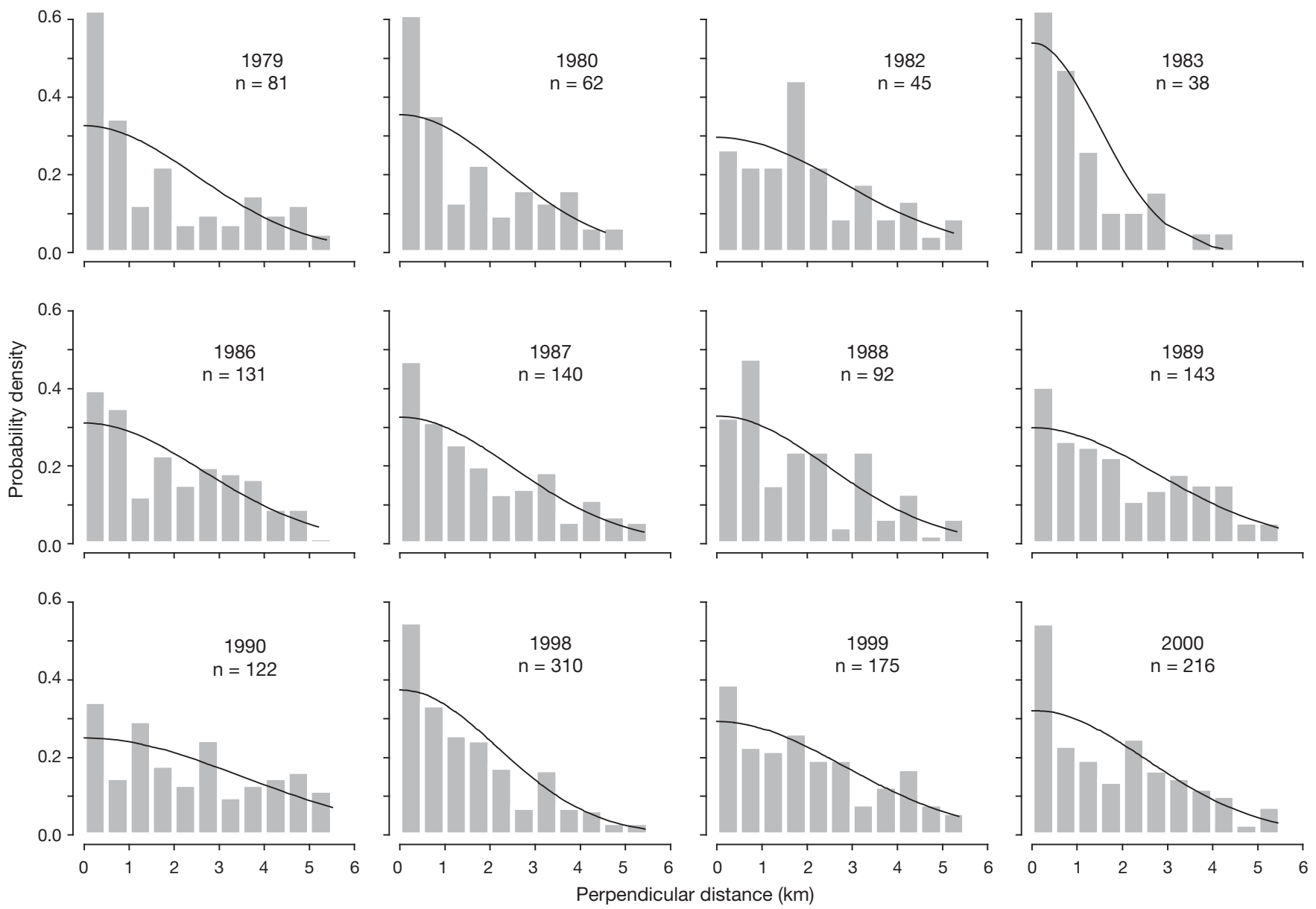

Fig. 3. Stenella attenuata. Frequency of sightings by perpendicular distance. Half-normal model fitted to the observations (without covariates)

\section{Trends}

Linear weighted least-squares regressions indicated positive but small increases for both NE offshore spotted $\left(0.3 \% \mathrm{yr}^{-1}, \mathrm{SE}=0.7 \%\right)$ and eastern spinner $\left(0.1 \% \mathrm{yr}^{-1}, \mathrm{SE}=1.0 \%\right)$ dolphins over the period 1979 to 2000 (Fig. 6). Quadratic regressions indicated a concave-upward curve for NE offshore spotted dolphins, and a concave-downward curve for eastern spinner dolphins. None of the regressions was statistically significant at the $\alpha=0.05$ level. A weighted LOESS smooth with span 1.5 through the NE offshore spotted estimates indicated a slight decline through the late 1980s and a slight increase $\left(<1 \% \mathrm{yr}^{-1}\right)$ since then (Fig. 7 ). A similar smooth through the eastern spinner estimates indicated an increasing population until 1990, followed by a decline of 2 to $3 \% \mathrm{yr}^{-1}$ until 2000 .

Given the number of estimates at the observed intervals and variance, the statistical power of detecting a 1 , $2,3,4$ or $5 \%$ annual rate of change between 1979 and 2000 using ordinary least-squares regression was estimated to be $0.26,0.67,0.95,1.0$ and 1.0 , respectively.

\section{DISCUSSION}

\section{Abundance}

Based on averages of the estimates from the 1998 to 2000 surveys, the current size of the NE offshore spotted dolphin population is about 640000 animals, and the current size of the eastern spinner dolphin population is about 450000 animals (Table 3). The estimates from the 3 most recent surveys agreed well with each other for both populations within the precision of the estimates (CVs of about 17 and $23 \%$, respectively; Fig. 6). The survey effort for eastern spinner dolphins in the outer stratum was small, relative to the large range of the dolphin stocks, in 1980, 1982 and 1983, and in 1999-2000 (Fig. 2). Estimates based on this sparse effort were less certain than in other years, and the bootstrap process probably underestimated the true uncertainty in these estimates.

The estimates of NE offshore spotted and eastern spinner dolphin abundance prior to 1998 presented in Table 3 differed from past estimates. Although some 

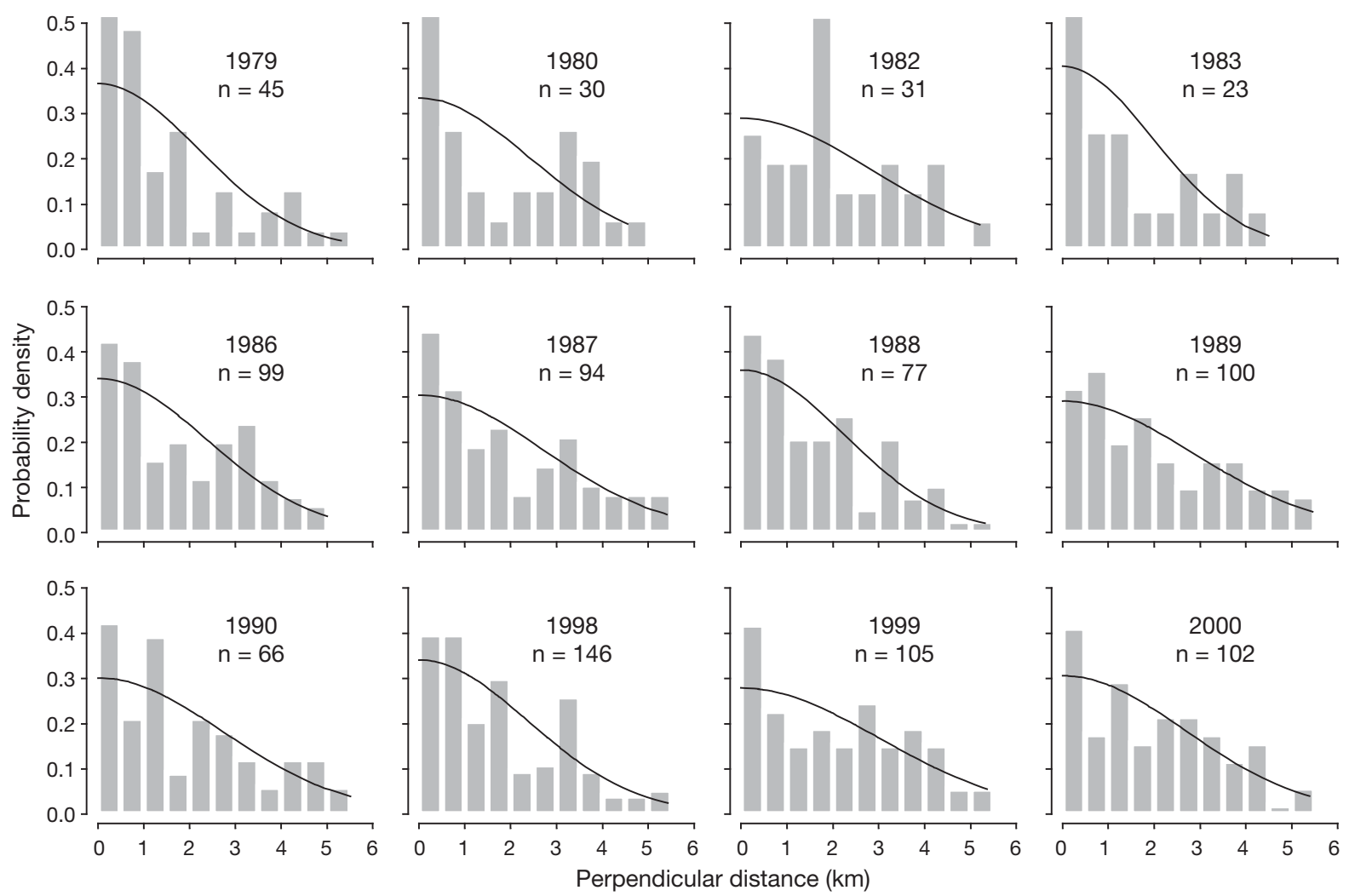

Fig. 4. Stenella longirostris. Frequency of sightings by perpendicular distance. Half-normal model fitted to the observations (without covariates)

estimates were higher and others lower, the main feature was that the estimates presented here were less variable among years than previous estimates. The differences between the old and new estimates were due to a number of changes, updates and improvements, both to the data and to the analysis. These included:

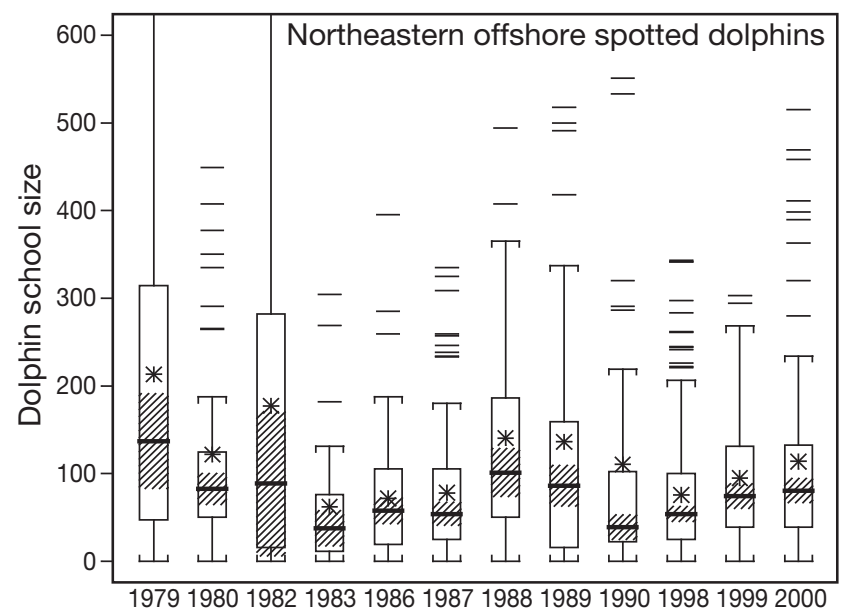

(1) explicit modeling of other factors (covariates) that affected probability of detection (Appendix 1); (2) implicit handling of school size detection bias; (3) AICweighted averaging of estimates from different models; (4) use of the half-normal model for the detection function across all years; (5) bias correction of school

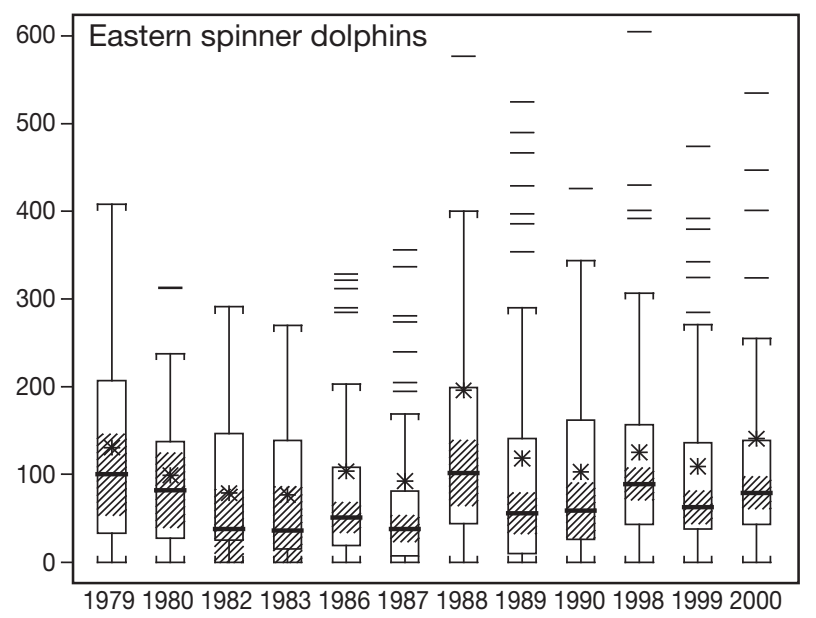

Fig. 5. Stenella attenuata attenuata and S. longirostris orientalis. Box-and-whisker plots of school size distributions, with means (*), medians (thick horizontal lines), $95 \%$ confidence intervals on the medians (hatched boxes), interquartile ranges (open boxes), and standard spans (whiskers and staples). Thin horizontal lines are outliers; both plots contain additional outliers that are not shown 

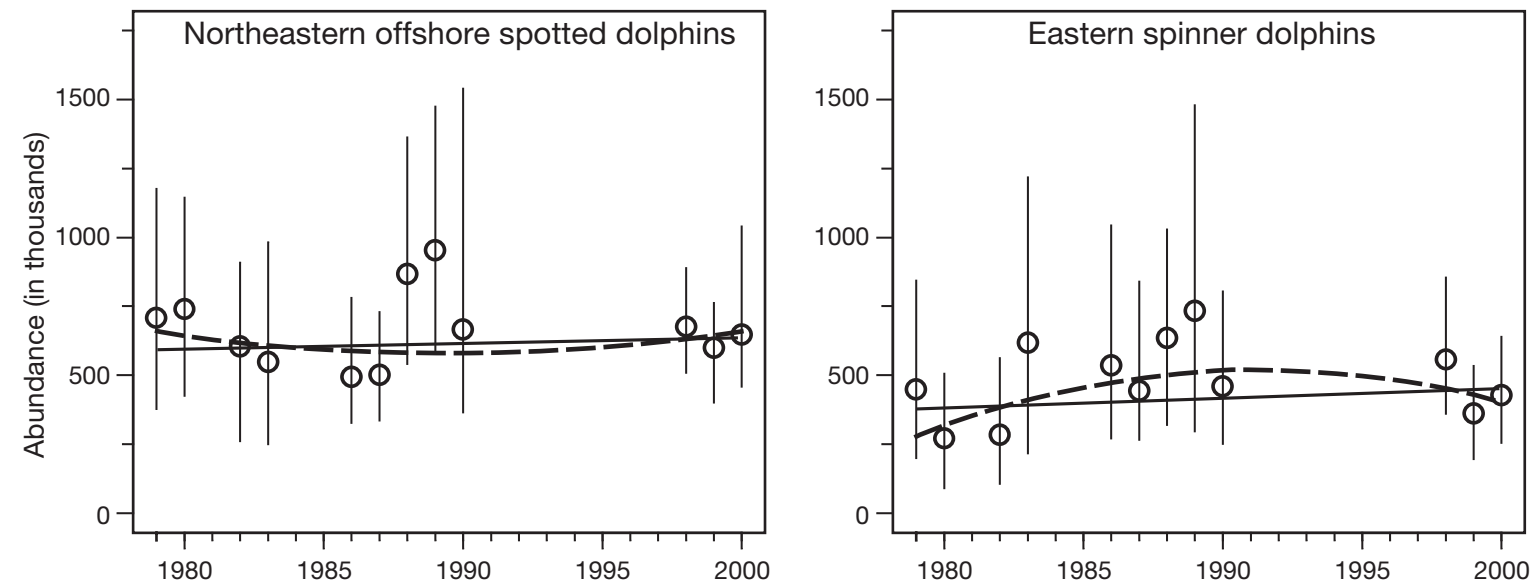

Fig. 6. Stenella attenuata attenuata and S. longirostris orientalis. Estimates of abundance 1979-2000, with 95\% confidence intervals (vertical lines), linear model (solid line) and quadratic model (dashed line)

size estimates based on aerial photography; (6) more accurate measurements of distance and area; (7) improved bootstrap procedures for estimating measures of precision; and (8) additional checking and editing of data for all years. Gerrodette \& Forcada (2002) discuss these factors in more detail.

Conventional line-transect methods use perpendicular distance from the trackline to estimate an effective strip width and rely on 'pooling robustness' to account for the multiple factors affecting whether an object is detected or not (Burnham et al. 1980). While they are widely used and generally robust, these methods have limitations (Ramsey \& Harrison 2004), and modeling the effects is an improved approach (Marques \& Buckland 2003, Forcada et al. 2004, Royle et al. 2004). For the dolphins considered here, the effects of covariates such as school size, sea state and sighting cue, in- cluding the presence of a bird flock, were important in modeling the probability of detection of a school (Table 2). Using generalized additive modeling for a wide variety of cetaceans, Barlow et al. (2001) also found school size, sea state and cue to be important predictors of mean perpendicular distance of detection. Similarly, Marques \& Buckland (2003), analyzing fishing vessel data for NE offshore spotted dolphins, found school size and sighting cue to be important factors. Sea state did not seem to be an important factor, but this may have been due to the more restricted range of Beaufort conditions considered by Marques \& Buckland (0 to 3, as opposed to 0 to 5 in this study and in Barlow et al.). Sea state is particularly important for less conspicuous species such as harbor porpoises Phocoena spp. (Jaramillo-Legorreta et al. 1999, Teilmann 2003).
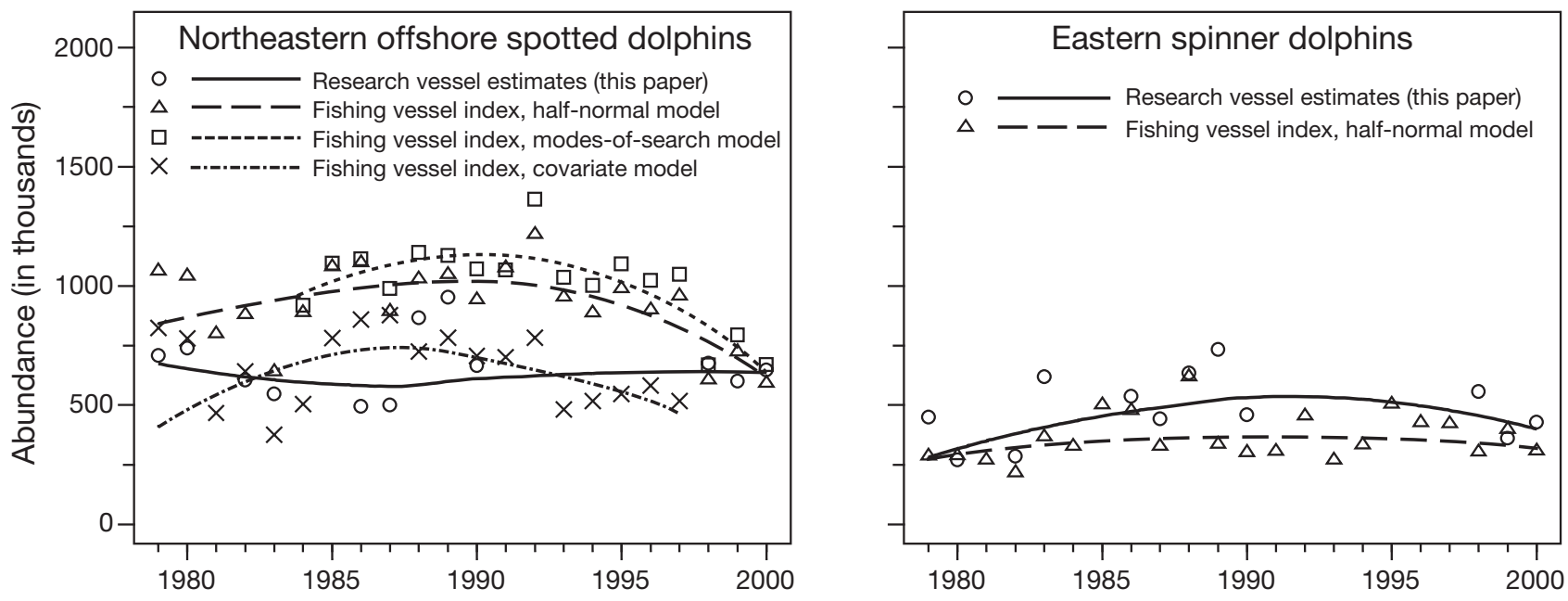

Fig. 7. Stenella attenuata attenuata and S. longirostris orientalis. Comparison of estimates of abundance 1979-2000, based on data from research vessel surveys (this study) with indices of abundance based on data collected by observers on fishing vessels. A weighted LOESS smoothed line is shown for each set of estimates 


\section{Bias}

For this study, the key assumptions of line-transect analysis were:

(1) Objects on the trackline are detected with certainty. For these large dolphin schools, the assumption is reasonable and generally supported (Brandon et al. 2002). However, a small percentage of schools were probably missed, leading to a slight underestimation of abundance.

(2) Objects are detected at their initial location. While these dolphins move away from survey vessels (Au \& Perryman 1982), most dolphin schools were sighted with $25 \times$ binoculars before they reacted significantly (Hewitt 1985, Brandon et al. 2002). Frequencies of sightings by perpendicular distance did not indicate avoidance prior to detection (Figs. 3 \& 4). Random movement of schools can cause a positive bias (Hiby 1982), but the speed of the vessel was high enough relative to normal dolphin movement for this effect to be small.

(3) Measurements are exact. On a moving ship, measurements of angles and distances to sightings are not exact. Use of angle rings and reticle scales improved accuracy, and the small systematic underestimation of distance due to refraction of light, with resulting overestimation of abundance, was corrected (Kinzey \& Gerrodette 2003). Even without systematic error, variability in distance measurements can lead to underestimation of abundance (Chen 1998); variability in this study (Kinzey \& Gerrodette 2003) was sufficiently low for this bias to be small. Exact determination of dolphin school sizes was not possible. However, the accuracy of group size estimates in this study was established by comparing estimates with aerial photographs. The general tendency to underestimate group size, with resulting negative bias in abundance estimates, was reduced by calibrating the estimates of individual observers (Gerrodette et al. 2002).

These surveys were conducted in closing mode, meaning that the ship left the trackline to approach dolphin sightings. This break in search effort was necessary to identify species and obtain accurate school size estimates, but may lead to undersampling of high density areas. Estimates of abundance using closing mode were negatively biased compared to passing mode, in which the ship does not leave the trackline, for Antarctic minke whales (Haw 1991, Branch \& Butterworth 2001a), but positively biased for most other cetaceans (Branch \& Butterworth 2001b). In surveys up to 1990, we closed on spotted and spinner schools only, whereas in 1998 to 2000, we closed on all cetacean sightings within $3 \mathrm{n}$ miles of the trackline. Because spotted and spinner dolphins have different habitat characteristics than other dolphins (Reilly \&
Fiedler 1994), this implies that the effect would have been weaker in the 1998 to 2000 surveys than earlier, if closing mode does create a negative bias by undersampling.

\section{Trends and recovery}

Contrary to the claim of Hall et al. $(2000, p$ 210) that 'recovery [of these dolphin stocks] is under way,' the data show that the stocks are not recovering at rates consistent with the estimated levels of depletion and current low reported levels of bycatch. Dolphin populations are estimated to be capable of growing at $4 \%$ $\mathrm{yr}^{-1}$ or more (Reilly \& Barlow 1986). For both stocks, the estimates did not show any statistically significant trend, either upwards or downwards, during the $21 \mathrm{yr}$ period (Fig. 6). The power analysis showed that if the dolphin populations had been growing (or declining) at a rate of $\geq 3 \% \mathrm{yr}^{-1}$ from 1979 to 2000 , there was high power $(>0.95)$ to detect that change. There was intermediate power $(0.67)$ to detect a $2 \% \mathrm{yr}^{-1}$ change, and low power $(0.26)$ to detect a $1 \% \mathrm{yr}^{-1}$ change. Thus, the non-significant regression analysis was not very informative about the smaller rates of change, as the standard errors also indicated. The lack of recovery of these dolphin stocks is in sharp contrast to 3 decades of actions (Gosliner 1999, Hall et al. 2000), which have reduced the dolphin bycatch by 2 orders of magnitude, from several hundred thousand dolphins per year (Wade 1995) to <2000 (Bayliff 2004).

Lennert-Cody et al. (2001) reached a similar conclusion about the lack of recovery based on analysis of data collected by observers on the fishing vessels. For NE offshore spotted dolphins, several indices of abundance were calculated, including estimates based on a univariate half-normal model (Lennert-Cody et al. 2001), a modes-of-search model which stratified data according to searching method (Lennert-Cody et al. 2001), and a sighting-covariate model (Marques 2001). For this stock, all fishing vessel indices showed an increasing population until about 1990, followed by a decline (Fig. 7). In contrast, the research vessel estimates (this study) did not indicate a decline in the last decade. For eastern spinner dolphins, the fishing vessel index was based on the half-normal model only and showed a similar trajectory to the estimates reported in this study (Fig. 7). Indices were positively correlated with abundance estimates for both NE offshore spotted and eastern spinner dolphins $(r=0.34$, $\mathrm{SE}=0.30$ and $\mathrm{r}=0.51, \mathrm{SE}=0.27$, respectively). For all indices derived from fishing vessel data, Lennert-Cody et al. (2001) cautioned that the data contain timevarying biases. After considering the possible size of these biases, however, the authors concluded that 'it 
seems unlikely that either of the stocks ... are increasing at rates that might be expected if they had been well below carrying capacity through the 1980s' (p 318).

\section{Hypotheses for lack of recovery}

There are several possible reasons why the dolphin populations are not recovering at expected rates.

(1) Dolphin bycatch is higher than reported. The Inter-American Tropical Tuna Commission, the fisheries commission which runs the international observer program and produces the bycatch estimates, reports that recent dolphin bycatch is known without error (Bayliff 2004). Observer coverage is close to $100 \%$ for the large (>363 mt) vessels which set on dolphins. Nevertheless, the reported number of dolphins killed is an underestimate, because: (a) smaller boats, which may sometimes set on dolphins, do not have observers; (b) observers do not see all of the net at all times on all sets; (c) some injured dolphins may die later (observers record 'severely injured' dolphins as mortalities); (d) dead dolphins, when observed, may not always be reported. The magnitude of underreporting due to these effects is not known. Furthermore, there is unobserved mortality of orphaned calves when lactating females are killed without their calves (Archer et al. 2004).

(2) Effects of the fishery go beyond bycatch. The annual number of dolphins chased, captured and released during fishing operations is high (Archer et al. 2002). Individual NE offshore spotted dolphins interact with the fishery between 2 and 50 times $\mathrm{yr}^{-1}$, depending on size of the school (Perkins \& Edwards 1999). It is likely that this rate of interaction has negative effects on survival and/or reproduction through stress (Curry 1999, Appendix 7 in Reilly et al. 2005), increased predation (Perryman \& Foster 1980), and separation of mothers and calves (Archer et al. 2001). Separation of mothers and calves may be due to disruption of the hydrodynamic drafting relationship between mother and calf during chase (Weihs 2004). In response to fishing activity, ETP dolphins have changed their behavior, becoming more evasive (Schramm Urrutia 1997, Heckel et al. 2000, Mesnick et al. 2002, Santurtún Oliveros \& Galindo Maldonado 2002, LennertCody \& Scott 2005). Seemingly small changes in behavior can have strong demographic effects (Gerrodette \& Gilmartin 1990). Differences in testes size indicate that eastern spinner dolphins have a more structured mating system than other subspecies of spinner dolphins, which may make them more vulnerable to frequent harassment (Perrin \& Mesnick 2003). Calf production has been declining since 1987 for both eastern spinner and NE offshore spotted dolphins (K. Cramer, W. Perryman, T.G. unpubl.). Although there are many probable cryptic effects of the fishery on dolphin vital rates, the actual magnitudes of these effects are not known.

(3) Dolphin habitat is not constant. NE offshore spotted and eastern spinner dolphins occur in the warm, stratified waters of the central part of the ETP (Reilly \& Fiedler 1994). Decadal-scale 'regime shifts' have been described in the North Pacific (Francis et al. 1998, Hare \& Mantua 2000, Chavez et al. 2003) and equatorial Pacific (McPhaden \& Zhang 2002). In the ETP, however, decadal variability is relatively low, El Niño-scale variability ( 2 to $7 \mathrm{yr}$ ) predominates, and average primary production does not appear to have declined since the late 1960s (Fiedler 2002). Since these dolphin populations are currently at 20 to $30 \%$ of their prefishery levels (Wade et al. 2002), a large decline in dolphin habitat would be necessary to explain the lack of dolphin recovery. Such a large change is not indicated by temporal patterns in oceanographic variables, ichthyoplankton, fish, squid, seabirds, other cetaceans, or dolphin habitat (reviewed in Appendix 6 of Reilly et al. 2005), although biological data are not available prior to 1986. A longer time-series from the fishery indicates an increase around 1985 in the abundance of yellowfin tuna (Maunder \& Harley 2004), which may indicate a change to more, not less, favorable habitat at that time for dolphins that associate with the tuna. Nevertheless, given fragmentary data and our limited understanding of how environmental changes affect dolphin abundance, we cannot rule out that ecosystem changes have negatively affected the recovery of the dolphin populations.

(4) Expectations of immediate recovery are oversimplified. Relatively simple single-species population models do not account for a variety of factors that might lead to a delay in, or perhaps even a failure of, dolphin recovery. Such factors could include competitive displacement by fish, sharks, or other cetaceans, depensatory ('Allee') effects at low population sizes, and disruptions to the age or social structure by past dolphin bycatch. Fisheries have a wide variety of effects on marine ecosystems (Dayton et al. 1995, Jennings \& Kaiser 1998, Pauly et al. 1998). In the oligotrophic ETP, competitive interactions are important in structuring the seabird community (Ballance et al. 1997), but other interspecific dynamics are poorly known. Most centrally, the ecological association of dolphins and yellowfin tuna, which forms the basis of the fishery, is still so little understood that we do not know whether the large removal of tuna biomass by the fishery in the last $40 \mathrm{yr}$ has had a positive, negative or neutral effect on dolphin population dynamics. Hutchings (2000) noted little evidence of recovery in 
90 fish stocks after $>15$ yr since fishing was reduced. On the other hand, Best (1993) described recovery in most baleen whale stocks after cessation of whaling. Modeling of the ETP ecosystem (Watters et al. 2003) may provide some insights about the effects of interspecific interactions as well as environmental change on recovery.

These hypotheses are not mutually exclusive. More than one may be responsible for the lack of dolphin recovery. Continued monitoring and ongoing research are aimed at evaluating which factors are most important.

Acknowledgements. Projects of this magnitude rely on the cooperative work of many people over many years. T. D. Smith led dolphin assessment studies in the 1970s. D. W. K. Au (1979), R. S. Holt (1980-1988), and L. T. Ballance (1999-2000) were chief scientists for the cruises (T.G. was chief scientist in other years). We collectively thank the dozens of observers who collected the data, the cruise leaders on various legs of the cruises, and the officers and crews of the research vessels. At the Southwest Fisheries Science Center, thanks to colleagues J. P. Barlow, J. R. Brandon, K. L. Cramer, R. C. Holland, A. R. Jackson, S. L. Martin, W. L. Perryman, and S. B. Reilly. The analysis benefited from the input of S. T. Buckland and T. Schweder at an October 2000 review sponsored by the Inter-American Tropical Tuna Commission. The final manuscript was improved by comments by T. D. Smith, W. F. Perrin, S. J. Chivers, P. C. Fiedler, and 3 anonymous reviewers. The 1998-2000 surveys were supported by the U.S. International Dolphin Conservation Program Act.

\section{LITERATURE CITED}

Archer F, Gerrodette T, Dizon A, Abella K, Southern Š (2001) Unobserved kill of nursing dolphin calves in a tuna purseseine fishery. Mar Mamm Sci 17:540-554

Archer F, Gerrodette T, Jackson A (2002). Preliminary estimates of the annual number of sets, number of dolphins chased, and number of dolphins captured by stock in the tuna purse-seine fishery in the eastern tropical Pacific, 1971-2000. Admin Rep LJ-02-10, Southwest Fisheries Science Center, La Jolla (available at: swfsc.ucsd.edu/ IDCPA/TunaDol_rep)

Archer F, Gerrodette T, Chivers S, Jackson A (2004) Annual estimates of the unobserved incidental kill of pantropical spotted dolphin (Stenella attenuata attenuata) calves in the tuna purse-seine fishery of the eastern tropical Pacific. Fish Bull 102:233-244

Au D, Perryman W (1982) Movement and speed of dolphin schools responding to an approaching ship. Fish Bull 80: 371-379

Au DWK, Pitman RL (1986) Seabird interactions with dolphins and tuna in the eastern tropical Pacific. Condor 88: 304-317

Ballance LT, Pitman RL, Reilly SB (1997) Seabird community structure along a productivity gradient: importance of competition and energetic constraint. Ecology 78: $1502-1518$

Barlow J, Gerrodette T, Perryman W (1998). Calibrating group size estimates for cetaceans seen on ship surveys. Admin Rep LJ-98-11, Southwest Fisheries Science Center La Jolla (available at: swfsc.ucsd.edu/IDCPA/TunaDol_rep)

Barlow J, Gerrodette T, Forcada J (2001) Factors affecting perpendicular sighting distances on shipboard linetransect surveys for cetaceans. J Cetacean Res Manag 3:201-212

Bayliff WH (ed) (2004) 2002 annual report. Inter-American Tropical Tuna Commission, La Jolla

Best PB (1993) Increase rates in severely depleted stocks of baleen whales. ICES J Mar Sci 50:169-186

Borchers DL, Buckland ST, Goedhart PW, Clarke ED, Hedley SL (1998) Horvitz-Thompson estimators for doubleplatform line transect surveys. Biometrics 54:1221-1237

Borchers DL, Buckland ST, Zucchini W (2002) Estimating animal abundance: closed populations. Springer-Verlag, London

Branch TA, Butterworth DS (2001a) Southern hemisphere minke whales: standardised abundance estimates from the 1978/79 to 1997/98 IDCR-SOWER surveys. J Cetacean Res Manag 3:143-174

Branch TA, Butterworth DS (2001b) Estimates of abundance south of $60^{\circ} \mathrm{S}$ for cetacean species sighted frequently on the $1978 / 79$ to $1997 / 98$ IWC/IDCR-SOWER sighting surveys. J Cetacean Res Manag 3:251-270

Brandon J, Gerrodette T, Perryman W, Cramer K (2002). Responsive movement and $g(0)$ for target species of research vessel surveys in the eastern tropical Pacific Ocean. Admin Rep LJ-02-02, Southwest Fisheries Science Center, La Jolla (available at: swfsc.ucsd.edu/IDCPA/TunaDol_rep)

Buckland ST (1992) Maximum likelihood fitting of hermite and simple polynomial densities. Appl Stat 41:241-266

Buckland ST, Anderson DR, Burnham KP, Laake JL, Borchers DL, Thomas L (2001) Introduction to distance sampling: estimating abundance of biological populations. Oxford University Press, New York

Burnham KP, Anderson DR (1998) Model selection and inference: a practical information-theoretic approach. Springer-Verlag, New York

Burnham KP, Anderson DR, Laake JL (1980) Estimation of density from line transect sampling of biological populations. Wildl Monogr 72:1-202

Chavez FP, Ryan J, Lluch-Cota SE, Niquen CM (2003) From anchovies to sardines and back: multidecadal change in the Pacific Ocean. Science 299:217-221

Chen SX (1998) Measurement errors in line transect surveys. Biometrics 54:899-908

Curry BE (1999) Stress in mammals: the potential influence of fishery-induced stress on dolphins in the eastern tropical Pacific Ocean. NOAA Tech Memo NMFS-SWFSC-260, NOAA, La Jolla

Davison AC, Hinkley DV (1997) Bootstrap methods and their application. Cambridge University Press, Cambridge

Dayton PK, Thrush SF, Agardy MT, Hofman RJ (1995) Environmental effects of marine fishing. Aquat Conserv 5:205-232

Dizon AE, Perrin WF, Akin PA (1994). Stocks of dolphins (Stenella spp. and Delphinus delphis) in the eastern tropical Pacific: a phylogeographic classification. NOAA Tech Rep NMFS 119, US Dept of Commerce, Seattle

Edwards EF, Perkins PC (1998) Estimated tuna discard from dolphin, school, and log sets in the eastern tropical Pacific Ocean, 1989-1992. Fish Bull 96:210-222

Efron B, Tibshirani R (1993) An introduction to the bootstrap. Chapman \& Hall, New York

Fiedler PC (2002) Environmental change in the eastern tropical Pacific Ocean: review of ENSO and decadal variability. Admin Rep LJ-02-16, Southwest Fisheries Science Center, La Jolla (available at: swfsc.ucsd.edu/IDCPA/ TunaDol_rep)

Forcada J (2002) Multivariate methods for size-dependent 
detection in conventional line transect sampling. Admin Rep LJ-02-07, Southwest Fisheries Science Center, La Jolla (available at: swfsc.ucsd.edu/IDCPA/TunaDol_rep)

Forcada J, Gazo M, Aguilar A, Gonzalvo J, Fernández-Contreras M (2004) Bottlenose dolphin abundance in the NW Mediterranean: addressing heterogeneity in distribution. Mar Ecol Prog Ser 275:275-287

Francis RC, Hare SR, Hollowed AB, Wooster WS (1998) Effects of interdecadal climate variability on the oceanic ecosystems of the NE Pacific. Fish Oceanogr 7:1-21

Gerrodette T (1987) A power analysis for detecting trends. Ecology 68:1364-1372

Gerrodette T (1993) TRENDS: software for a power analysis of linear regression. Wildl Soc Bull 21:515-516

Gerrodette T (2002) The tuna-dolphin issue. In: Perrin WF, Würsig B, Thewissen JGM (eds) Encyclopedia of marine mammals. Academic Press, San Diego, p 1269-1273

Gerrodette T, Forcada J (2002) Estimates of abundance of northeastern offshore spotted, coastal spotted, and eastern spinner dolphins in the eastern tropical Pacific Ocean. Admin Rep LJ-02-06, Southwest Fisheries Science Center, La Jolla (available at: swfsc.ucsd.edu/IDCPA/TunaDol_rep)

Gerrodette T, Gilmartin WG (1990) Demographic consequences of changed pupping and hauling sites of the Hawaiian monk seal. Conserv Biol 4:423-430

Gerrodette T, Perryman W, Barlow J (2002) Calibrating group size estimates of dolphins in the eastern tropical Pacific Ocean. Admin Rep LJ-02-08, Southwest Fisheries Science Center, La Jolla (available at: swfsc.ucsd.edu/IDCPA/ TunaDol_rep)

Gilpatrick JW Jr (1993) Method and precision in estimation of dolphin school size with vertical aerial photography. Fish Bull 91:641-648

Gordon JCD (1990) A simple photographic technique for measuring the length of whales from boats at sea. Rep Int Whal Comm 40:581-588

Gosliner ML (1999) The tuna-dolphin controversy. In: Twiss JR Jr, Reeves RR (eds) Conservation and management of marine mammals. Smithsonian Institution Press, Washington, DC, p 120-155

Hall MA (1998) An ecological view of the tuna-dolphin problem: impacts and trade-offs. Rev Fish Biol Fish 8:1-34

Hall MA, Alverson DL, Metuzals KI (2000) By-catch: problems and solutions. Mar Poll Bull 41:204-219

Hare SR, Mantua NJ (2000) Empirical evidence for North Pacific regime shifts in 1977 and 1989. Prog Oceanogr 47:103-145

Haw MD (1991) An investigation into the differences in minke whale school density estimates from passing mode and closing mode survey in IDCR Antarctic assessment cruises. Rep Int Whal Comm 41:313-330

Hayes RJ, Buckland ST (1983) Radial distance models for the line transect method. Biometrics 39:29-42

Heckel G, Murphy KE, Compeán Jiménez GA (2000) Evasive behavior of spotted and spinner dolphins (Stenella attenuata and $S$. longirostris) during fishing for yellowfin tuna (Thunnus albacares) in the eastern Pacific Ocean. Fish Bull 98:692-703

Hedley C (2001) The 1998 Agreement on the International Dolphin Conservation Program: recent developments in the tuna-dolphin controversy in the eastern Pacific Ocean. Ocean Dev Int Law 32:71-92

Hewitt RP (1985) Reaction of dolphins to a survey vessel: effects on census data. Fish Bull 83:187-193

Hiby AR (1982) The effect of random whale movement on density estimates obtained from whale sighting surveys. Rep Int Whal Comm 32:791-793
Holt RS, Gerrodette T, Cologne JB (1987) Research vessel survey design for monitoring dolphin abundance in the eastern tropical Pacific. Fish Bull 85:435-446

Hoyle SD, Maunder MN (2004) A Bayesian integrated population dynamics model to analyze data for protected species. Anim Biodiv Conserv 27.1:247-266

Hurvich CM, Tsai CL (1989) Regression and time series model selection in small samples. Biometrika 76:297-307

Hutchings JA (2000) Collapse and recovery of marine fishes. Nature 406:882-885

Jaramillo-Legorreta AM, Rojas-Bracho L, Gerrodette T (1999) A new abundance estimate for vaquitas: first step for recovery. Mar Mamm Sci 15:957-973

Jennings S, Kaiser MJ (1998) The effects of fishing on marine ecosystems. Adv Mar Biol 34:201-352

Joseph J (1994) The tuna-dolphin controversy in the eastern Pacific Ocean: biological, economic, and political impacts. Ocean Dev Int Law 25:1-30

Kinzey D, Gerrodette T (2001) Conversion factors for binocular reticles. Mar Mamm Sci 17:353-361

Kinzey D, Gerrodette T (2003) Distance measurements using binoculars from ships at sea: accuracy, precision and effects of refraction. J Cetacean Res Manag 5:159-171

Kinzey D, Olson P, Gerrodette T (2000) Marine mammal data collection procedures on research ship line-transect surveys by the Southwest Fisheries Science Center. Admin Rep LJ-00-08, Southwest Fisheries Science Center, La Jolla (available at: swfsc.ucsd.edu/IDCPA/TunaDol_rep)

Lennert-Cody CE, Scott MD (2005) Spotted dolphin evasive response in relation to fishing effort. Mar Mamm Sci 21: $13-28$

Lennert-Cody CE, Buckland ST, Marques FFC (2001) Trends in dolphin abundance estimated from fisheries data: a cautionary note. J Cetacean Res Manag 3:305-319

Lerczak JA, Hobbs RC (1998) Calculating sighting distances from angular readings during shipboard, aerial and shorebased marine mammal surveys. Mar Mamm Sci 14:590-599

Marques FFC (2001) Estimating wildlife distribution and abundance from line transect surveys conducted from platforms of opportunity. PhD thesis. University of St. Andrews

Marques FFC, Buckland ST (2003) Incorporating covariates into standard line transect analyses. Biometrics 59:924-935

Maunder MN, Harley SJ (2004) Status of yellowfin tuna in the eastern Pacific Ocean in 2002 and outlook for 2003. IATTC Stock Assess Rep 4:5-91

McPhaden MJ, Zhang D (2002) Slowdown of the meridional overturning circulation in the upper Pacific Ocean. Nature 415:603-608

Mesnick SL, Archer FI, Allen AC, Dizon AE (2002) Evasive behavior of eastern tropical Pacific dolphins relative to effort by the tuna purse-seine fishery. Admin Rep LJ-0230, Southwest Fisheries Science Center, La Jolla (available at: swfsc.ucsd.edu/IDCPA/TunaDol_rep)

NRC (National Research Council) (1992) Dolphins and the tuna industry. National Academy Press, Washington, DC

Pauly D, Christensen V, Dalsgaard J, Froese R, Torres F Jr (1998) Fishing down marine food webs. Science 279: 860-863

Perkins PC, Edwards EF (1999) Capture rate as a function of school size in pantropical spotted dolphins, Stenella attenuata, in the eastern tropical Pacific Ocean. Fish Bull 97:542-554

Perrin WF (1990) Subspecies of Stenella longirostris (Mammalia: Cetacea: Delphinidae). Proc Biol Soc Wash 103: 453-463

Perrin WF, Mesnick SL (2003) Sexual ecology of the spinner 
dolphin, Stenella longirostris: geographic variation in mating system. Mar Mamm Sci 19:462-483

Perrin WF, Schnell GD, Hough DJ, Gilpatrick JW Jr, Kashiwada JV (1994) Reexamination of geographic variation in cranial morphology of the pantropical spotted dolphin, Stenella attenuata, in the eastern Pacific. Fish Bull 92: 324-346

Perryman WL, Foster TC (1980) Preliminary report on predation by small whales, mainly the false killer whale, Pseudorca crassidens, on dolphins (Stenella spp. and Delphinus delphis) in the eastern tropical Pacific. Admin Rep LJ-80-05, Southwest Fisheries Science Center, La Jolla (available at: swfsc.ucsd.edu/IDCPA/TunaDol_rep)

Quinn TJ II, Gallucci VF (1980) Parametric models for linetransect estimators of abundance. Ecology 61:293-302

Ramsey FL, Harrison K (2004) A closer look at detectability. Environ Ecol Stat 11:73-84

Ramsey FL, Wildman V, Engbring J (1987) Covariate adjustments to effective area in variable-area wildlife surveys. Biometrics 43:1-11

Reilly SB (1990) Seasonal changes in distribution and habitat differences among dolphins in the eastern tropical Pacific. Mar Ecol Prog Ser 66:1-11

Reilly SB, Barlow J (1986) Rates of increase in dolphin population size. Fish Bull 84:527-533

Reilly SB, Fiedler PC (1994) Interannual variability of dolphin habitats in the eastern tropical Pacific. I: Research vessel surveys, 1986-1990. Fish Bull 92:434-450

Reilly SB, Donahue MA, Gerrodette T, Forney K and 8 others (2005) Report of the scientific research program under the International Dolphin Conservation Program Act. NOAA Tech Memo NMFS-SWFSC-372. (also available at http:// swfsc.nmfs.noaa.gov/IDCPA/TunaDol_rep/)

Royle JA, Dawson DK, Bates S (2004) Modeling abundance effects in distance sampling. Ecology 85:1591-1597

Santurtún Oliveros E, Galindo Maldonado F (2002) Coping behaviors of spotted dolphins during fishing sets. Admin Rep LJ-02-36C, Southwest Fisheries Science Center, La
Jolla (available at: swfsc.ucsd.edu/IDCPA/TunaDol_rep) Schramm Urrutia Y (1997) Nivel de actividad de los delfines manchado Stenella attenuata y tornillo oriental S. longirostris, en redes atuneras, en el Océano Pacífico Oriental. MS thesis, Universidad Autónoma de Baja California, Ensenada, BC

Smith TD (1983) Changes in size of three dolphin (Stenella spp.) populations in the eastern tropical Pacific. Fish Bull 81:1-13

Teilmann J (2003) Influence of sea state on density estimates of harbour porpoises (Phocoena phocoena). J Cetacean Res Manag 5:85-92

Wade PR (1993) Estimation of historical population size of the eastern spinner dolphin (Stenella longirostris orientalis). Fish Bull 91:775-787

Wade PR (1995) Revised estimates of incidental kill of dolphins (Delphinidae) by the purse-seine tuna fishery in the eastern tropical Pacific, 1959-1972. Fish Bull 93: 345-354

Wade PR, Gerrodette T (1992) Estimates of dolphin abundance in the eastern tropical Pacific: preliminary analysis of 5 years of data. Rep Int Whal Comm 42:533-539

Wade PR, Gerrodette T (1993) Estimates of cetacean abundance and distribution in the eastern tropical Pacific. Rep Int Whal Comm 43:477-493

Wade PR, Reilly SB, Gerrodette T (2002) Assessment of the population dynamics of the northeast offshore spotted and the eastern spinner dolphin populations through 2002. Admin Rep LJ-02-13, Southwest Fisheries Science Center, La Jolla (available at: swfsc.ucsd.edu/IDCPA/ TunaDol_rep)

Watters GM, Olson RJ, Francis RC, Fiedler PC and 7 others (2003) Physical forcing and the dynamics of the pelagic ecosystem in the eastern tropical Pacific: simulations with ENSO-scale and global-warming climate drivers. Can J Fish Aquat Sci 60:1161-1175

Weihs D (2004) The hydrodynamics of dolphin drafting. J Biol 3:8 
Appendix 1. Detection function models and abundance estimators

The multivariate detection probability model $g(x, C)$ is defined as the conditional probability of sighting a dolphin group given its perpendicular distance $x$ from the transect line and $\underline{C}$, a vector with its size (number of individuals) and additional detection covariates (sea state, sighting cue, survey platform, etc). Perpendicular distances are assumed to follow a uniform distribution between the transect line and truncation distance $W: x \sim I(0, W)$. With transect lines allocated randomly in the survey area, perpendicular distances are assumed to be independent of group size and other covariates. Thus, the unconditional probability of detecting a group is

$$
P=\iint_{W} g(x, \underline{c}) f(x, \underline{c}) \mathrm{d} x \mathrm{~d} \underline{\underline{C}}=W^{-1} \iint_{W} g(x, \underline{c}) f(\underline{c}) \mathrm{d} x \mathrm{~d} \underline{C}
$$

where $f(x, \underline{c})$ is the joint probability density function ( $p d f)$ of observed perpendicular distances and group size and additional covariates, $\underline{C}$, expressed as

$$
f(x, \underline{c})=\frac{g(x, \underline{C}) f(\underline{c})}{\iint_{W} g(x, \underline{c}) f(\underline{C}) \mathrm{d} x \mathrm{~d} \underline{\underline{C}}}
$$

This function requires knowledge of the form of $f(\underline{c})$. In order to avoid this problem the function is better expressed as a conditional $p d f$ of $x$ given $\underline{C}$, i.e., $f\left(\left.x\right|_{\underline{C}}\right)$, as

$$
f(x \mid \underline{c})=\frac{g(x, \underline{c})}{\int_{0}^{W} g(x, \underline{c}) \mathrm{d} x}=\frac{g(x, \underline{c})}{\mu(\underline{c})}
$$

The integral in Eq. (A3) is $\mu(\underline{c})$, the effective strip half-width under conditions $\underline{C}$, which divided by $W$ is the average probability that a dolphin school with covariates $\underline{\underline{C}}$ is detected.

Assuming perfect detection on the transect line, the conditional $p d f$ can be evaluated at 0 to estimate $\mu(\underline{c})$

$$
\hat{f}(0 \mid \underline{c})=\frac{g(0 \mid \underline{c})}{\hat{\mu}(\underline{c})}=\frac{1}{\hat{\mu}(\underline{c})}
$$

Estimates $\hat{f}(0 \mid \underline{C})$ were obtained with conditional multivariate detection function models in which covariates affect the scale parameter (Ramsey et al. 1987, Forcada 2002, Marques \&
Buckland 2003). Covariates $C$ were assumed to have multiplicative effects (additive in a log scale) of the form

$$
\alpha(\underline{c})=\exp \left\{\alpha_{0}+\sum_{k} \alpha_{k} \log \left(c_{k}\right)\right\}
$$

in 2 competing parametric models, the hazard rate detection model (Hayes \& Buckland 1983)

$$
g(x \mid \underline{C})=1-\exp \left\{\left[-\frac{x}{\alpha(\underline{c})}\right]^{-b}\right\}
$$

where $b$ is a shape parameter, and the half-normal model (Quinn \& Gallucci 1980)

$$
g(x \mid \underline{C})=\exp \left\{-\frac{1}{2}\left[\frac{x}{\alpha(\underline{C})}\right]^{2}\right\}
$$

Horvitz-Thompson-like (Borchers et al. 1998) line-transect estimators have the general form

$$
\hat{N}=\frac{A}{a_{W}} \sum_{i=1}^{n} \frac{1}{E\left[p\left(x_{i}, \underline{c}_{i}\right)\right]}
$$

where $A$ is the total area, $a_{W}=2 L W$ is the area surveyed, obtained by combining total transect length $L$ and righttruncation distance $W$, and $E$ is the expectation operator. Inverse detection probabilities $p$ are summed over the $n$ detected groups during the sampling of area $A$.

Expressed as a conditional probability, from Eqs. (A1) to (A3),

$$
\begin{aligned}
E[p(x \mid \underline{c})] & =W^{-1} \int_{0}^{W} g(x \mid \underline{c}) \mathrm{d} x \\
& =W^{-1} \mu(\underline{c}) \\
& =[W f(0 \mid \underline{c})]^{-1}
\end{aligned}
$$

Using this term in Eq. (A8), the abundance of dolphin schools is

$$
\hat{N}=\frac{A}{2 L} \sum_{i=1}^{n} \hat{f}_{i}\left(0 \mid \underline{C}_{i}\right)
$$

and the estimators of dolphin abundance and bias-corrected mean group size are derived similarly.

Submitted: October 8, 2004; Accepted: January 15, 2005 Proofs received from author(s): April 20, 2005
Editorial responsibility: Otto Kinne (Editor-in-Chief), Oldendorf/Luhe, Germany 